AN EXPLORATORY STUDY OF COHESION AMONG CO-LOCATED AND VIRTUAL MEMBERS OF VIRTUAL, PARTIALLY DISTRIBUTED GROUPS

A Dissertation
presented to
the Faculty of the Graduate School
at the University of Missouri-Columbia
In Partial Fulfillment
of the Requirements for the Degree
Doctor of Education
SANDRA HARDING
Dr. Cynthia MacGregor, Dissertation Supervisor

July 2020 
The undersigned, appointed by the dean of the Graduate School, have examined the dissertation entitled

\section{AN EXPLORATORY STUDY OF COHESION AMONG CO-LOCATED AND VIRTUAL MEMBERS OF VIRTUAL, PARTIALLY DISTRIBUTED GROUPS}

Presented by Sandra Lynn Harding, A candidate for the degree of doctor of education in educational leadership, and hereby certify that, in their opinion, it is worthy of acceptance.

Professor Cynthia MacGregor

Professor Jeffrey Cornelius-White

Professor Ximena Uribe-Zarain

Professor Jon S. Turner 


\section{DEDICATION}

I want to thank Colin for his support during the writing of this dissertation.

Through all of the times I wanted to give up and during all my tears and fits of

frustration, he encouraged me to keep believing in myself and to see this journey to its conclusion. 


\section{ACKNOWLEDGMENTS}

There are a few people I want to thank for helping my this dream a reality. Dr. Jeffrey Cornelius-White, my advisor for most of the dissertation process, provided his knowledge and expertise. I appreciate his efforts to keep me on track. I also want to thank my committee members, Dr. Ximena Uribe-Zarain, Dr. Jon S. Turner, and Dr. Cynthia MacGregor. I would like to give a special thanks to Dr. Cynthia MacGregor. Not only was she a committee member, she was the professor for several of my doctoral courses and my final dissertation advisor. Without her encouragement and guidance during coursework, answering questions throughout the process, and dedication to honoring her statement that the only thing we could not fix is if we quit, I would not have completed the program and dissertation. 


\section{TABLE OF CONTENTS}

ACKNOWLEDGEMENTS ................................................ii

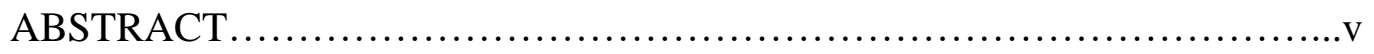

SECTION ONE: INTRODUCTION TO DISSERTATION ....................

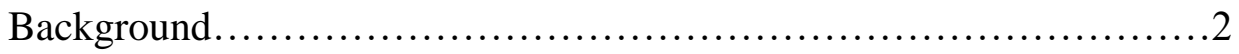

Statement of Problem............................................4

Purpose of Study and Research Questions..........................5

Conceptual Framework........................................

Design of the Study..........................................

Limitations, Delimitations, Assumptions................................15

Definition of Key Terms.............................................................18

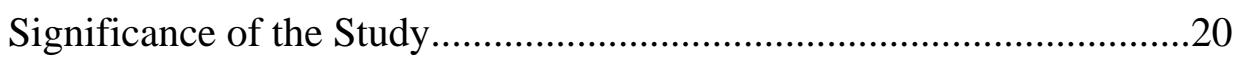

SECTION TWO: PRACTITIONER SETTING ............................................24

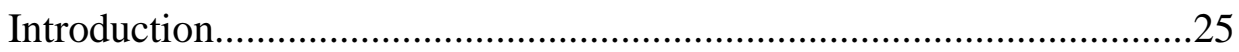

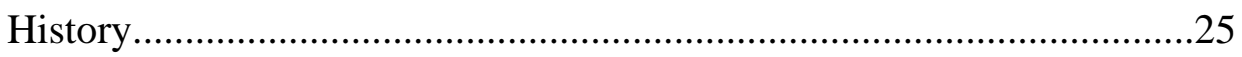

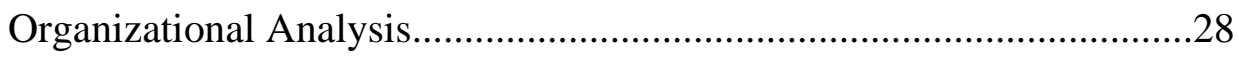

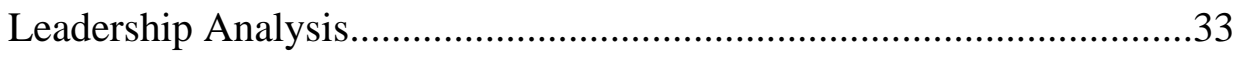

Implication for Research in Practitioner Setting...................................37

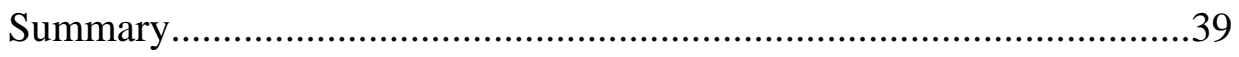

SECTION THREE: SCHOLARLY REVIEW .........................................42

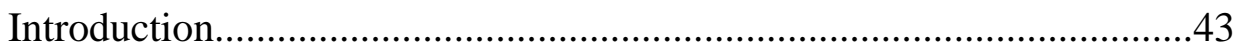

Co-located Group Cohesion..........................................................43

Virtual Group Cohesion.............................................................44 
Virtual, Partially Distributed Groups.................................................46

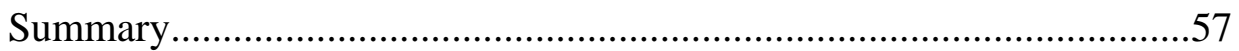

SECTION FOUR: CONTRIBUTION TO PRACTICE..................................59

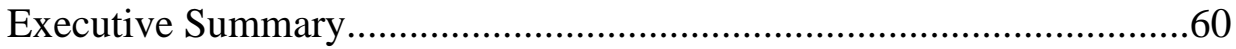

PowerPoint Presentation...................................................................61

SECTION FIVE CONTRIBUTION TO SCHOLARSHIP..............................69

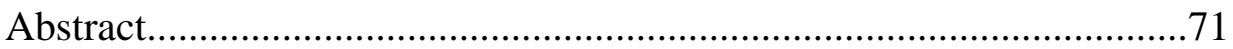

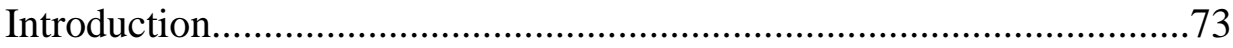

Purpose

Literature Review...................................................................... 75

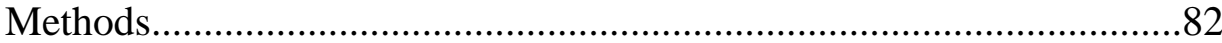

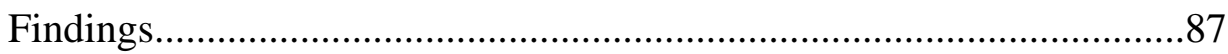

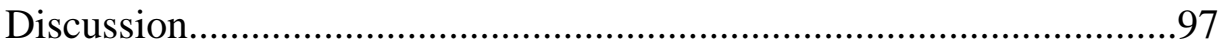

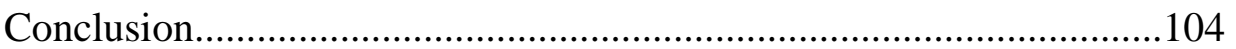

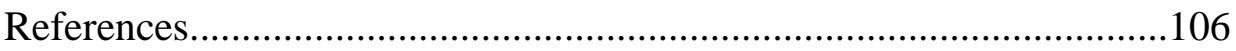

SECTION SIX: SCHOLARLY PRACTITIONER REFLECTION..................114

Influence on Practice................................................................115

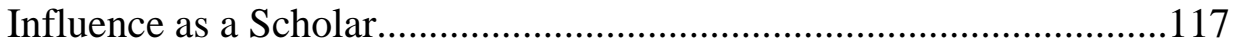

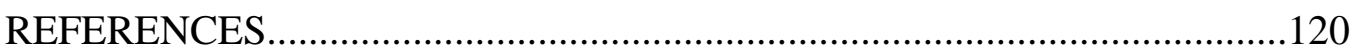

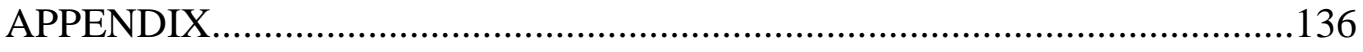

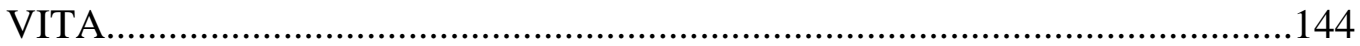


AN EXPLORATORY STUDY OF COHESION AMONG CO-LOCATED AND VIRTUAL MEMBERS OF VIRTUAL, PARTIALLY DISTRIBUTED GROUPS

\author{
Sandra Harding \\ Dr. Cynthia MacGregor, Dissertation Supervisor
}

\begin{abstract}
This study provides insight into the factors of cohesion and its development in virtual, partially distributed groups. This qualitative exploratory research design examined how co-located and virtual group participants experienced cohesion. Participants were part of a doctoral cohort. Data was gathered using a demographic survey and individual interviews. Data analysis was accomplished through open, focused, and axial coding using constant comparison and inductive reasoning to identify categories. Findings indicate virtual and co-located participants expressed a sense of cohesion in both task and social areas. Factors of task cohesion include having a shared goal, a commitment to goal achievement and overcoming challenges. Factors of social cohesion include identification with group members, open communication, sharing personal life information and informal socializing which were all components of relationship building. Virtual participants were more focused on factors affecting individual task cohesion (commitment to goal) and individual social cohesion (identification with other members) than those impacting group cohesion. Practitioners should consider using a strengths assessment when forming a new group. They should also provide group dynamics resources and clearly defined group objectives.
\end{abstract}


SECTION ONE:

INTRODUCTION TO DISSERTATION 


\section{Background}

Ralph Waldo Emerson said, "No member of a crew is praised for the rugged individuality of his rowing" (Karvelas, 1998, p. 67). Helen Keller shared "Alone we can do so little; together we can do so much" (Lash, 1980, p. 489). Halford E. Luccock held "No one can whistle a symphony. It takes a whole orchestra to play it" (Karvelas, 1998, p.31). What do these quotes have in common?

Each of these passages refers to groupwork and group cohesion. Although these quotes are not contemporary, they are classics and remain applicable. Group cohesion is well researched. It is one of the most widely studied aspects of group dynamics (McLeod \& von Treuer, 2013). Research shows that group cohesion has a positive effect on group performance (Greer, 2012). That group cohesion impacts a group's success makes it an important group dynamic variable therefor research regarding group cohesion has both scholarly and practical application.

Technology in the past few decades has introduced a new facet to group or groupwork that is now commonplace, but under-studied. Today, many groups work disparately, in far-flung locations. Yet, they are still able to work together toward a common goal collaborating on company or organizational projects (Großer\& Baumöl, 2017). There are three types of distributed collaborative groups. In virtual groups all members participate via virtual communication technology rather than traditional face-toface (Haines, 2014). Co-located groups with two or more groups meeting in geographically disparate locations using virtual communication technology to collaborate between groups are another type (Daim et al., 2012). The third, and the type of group this study will research, is a virtual, partially distributed group. Members in this type of group 
are both co-located and geographically dispersed (Eubanks, Palanski, Olabisi, Joinson, \& Dove, 2016).

All types of virtual groups have been on the rise in recent years (Blair, 2015). Corporations have steadily increased the number of telecommuting employees (Global Workplace Analytics, 2017). Advances in technology, especially that related to real-time visual and verbal communication, have made it possible for people to study and work together without the need to be physically present with one another, and having the option to live anywhere is very appealing to many (Radu, 2018; Grinnell, Sauers, Appunn, \& Mack, 2012).

One area utilizing virtual groups is higher education. Online courses have become increasingly popular with both educational institutions and students (Grinnell et al., 2012). This also allows students to pursue educational opportunities beyond a restricted commuting circumference around a brick and mortar institutional location. Benefits for students include lower commuting times which reduces fuel use. Universities need fewer facilities decreasing the associated costs of upkeep, heating and cooling, and technology upgrades to older buildings.

All stakeholders involved in higher education are interested in student success. Those courses in which students are participating using virtual communication technology present new challenges in ensuring student achievement. The goal of this research was to explore the aspects of group cohesion of both co-located students and those participating using virtual communication technology because group cohesion has been shown to affect performance and success. 


\section{Statement of the Problem}

People working in groups to accomplish tasks is not new. Performing group tasks without members being physically together is rising. One area which has seen an increase in virtual collaboration is higher education with the use of online course enrollment (Cherney, Fetherston, \& Johnsen, 2018). Distance education courses can be completely online or blended. In a blended course, students have some seat time within a traditional classroom setting combined with the use of virtual communication technology. Distance learning has evolved from isolated, independent student assignment completion to collaborative group learning incorporating individual and group projects (Cherney et al., 2018). Project based learning requires students to collaborate in groups to learn, problemsolve, and achieve a shared goal (Kokotsaki, Menzies, \& Wiggins, 2016).

Groupwork has many challenges: individual personality traits and conflicts (Kramer, Bhave, \& Johnson, (2014), specific goals and deadlines (Maynard, Mathieu, Gilson, Sanchez, \& Dean, 2018), internal and external competition (Yuan, Tu, Li, \& Ning, 2018), groupthink (Gardner \& Quigley, 2015), supervisor or instructor expectations (Vosloban, 2012), individual engagement (Robert \& You, 2018), and a common purpose (Salas, Reyes \& McDaniel, 2018).

Cohesion is a vital part of group dynamics (Paul, Drake, \& Liang, 2016). Colocated groups, those meeting in the same actual place and time, are challenged to develop and maintain cohesion (Yilmaz \& Peña, 2014). Virtual groups may experience these same challenges with the added facet of using technology to meet as a group and accomplish tasks without being physically together (Levi, 2014). Group cohesion is not static. It occurs over time through the interactions of group members and may differ in 
development given various situations and circumstances (Lu, 2015). Many studies recommend future research to include empirical studies to explore the development or phases of group cohesion, yet the literature is still weak in this area (Greer, 2012).

Many groups — work, educational, and social — are either completely co-located or completely virtual and dispersed. Another form is a hybrid in which some group members meet in the traditional face-to-face fashion while other members interact with the group strictly via virtual communication technology. Eubanks et al. (2016) call this type of hybrid group a virtual, partially distributed team.

Little research has been published regarding virtual, partially distributed groups. The subject of this study, a statewide cooperative education doctorate cohort, had its first virtual, partially distributed group of students. Given the importance of group cohesion on member satisfaction and group performance, it is essential to explore how members of this type of group experience cohesion.

\section{Purpose of the Study}

This study endeavors to add to previous research on group cohesion focusing on a single, specific doctoral program with five cohorts, consisting of virtual, partially distributed members. The purpose was to discover how the cohort members experience group cohesion during the coursework portion of the program. Berry (2017) found that students who are part of a cohort experience a sense of cohesion because they have the same goal, begin coursework simultaneously, and progress through their program together. The study applied the methods and measures use by von Treuer, FullerTyszkiewicz, Moss, McLeod, \& Hamilton, (2013). von Treuer and colleagues sought to create an appropriate measure of group cohesion. They asked about experiences of group 
members and applied content analysis to examine the data. This study used similar research questions and applied content analysis in a comparable manner.

Although research regarding group dynamics is plentiful, the literature on virtual group participants has large gaps, especially empirical studies (Paul et al., 2016; O’Neill \& Allen, 2014). In contrast, there is a significant amount of theoretical conceptualization that has been published regarding virtual groups (e.g., Gilson, Maynard, Young, Vartiainen, \& Hokonen, 2014). Virtual groups face many of the same issues as co-located groups (Levi, 2014). However, the fact that group members collaborate virtually adds new facets to issues experienced by any group and presents some new unique challenges (Haines, 2014).

The literature often mentions group cohesiveness as an important factor for virtual member and group performance (Marlow, Lacerenza, \& Salas, 2017; Ferrara, Mohammadi, Taylor, \& Javernick-Will, 2017; Gibbs, Sivunen, \& Boyraz 2017). What is missing in the research are empirical studies of the components identifying group cohesion and assessing, with similar methodologies, to what extent those components are similar or different for virtual, partially distributed groups. It is likely that virtual member participants experience group cohesion differently than the co-located members within this virtual, partially distributed cohort. Because group cohesion is developmental, it may progress differently for co-located group members than for those members participating using virtual communication technology. Understanding and to better facilitate cohesion within this virtual, partially distributed cohort could be helpful for their success.

This research adds to current research on group cohesion concentrating on five doctoral virtual, partially distributed cohorts to explore the following research questions. 
RQ 1: How is cohesion experienced by virtual participants in a virtual, partially distributed group?

RQ 2: How is cohesion experienced by co-located participants in a virtual, partially distributed group?

\section{Conceptual Framework}

The conceptual foundation of group cohesion for this study encompasses task and social cohesion while considering group cohesion's progressive development. This study was not intended to test variables, such as trust or types of communication, as a means of measuring group cohesion. Instead, the goal was to discover how a virtual, partially distributed educational doctorate cohort's virtual and co-located members experience group cohesion. Group cohesion was treated as an emergent state allowing for the capture of the temporal nature of its development.

Social cohesion and task cohesion are commonly used terms to distinguish between activities revolving around a specific goal (task) or undertaking by a group and those related to interpersonal relationships (social) (Carless \& De Paola, 2000). The participants in this study were united in achieving a common task which will be completing a group project. The experiences of social cohesion differ for co-located group members versus those participating through virtual communication.

Developmentally, task cohesion occurred quickly while social cohesion progressed as the group members interact and collaborate to complete their common task.

Marks, Mathieu, and Zaccaro (2001) differentiated between the emergent state of cohesion and processes that represent group interaction. Their research suggests that group cohesion is demonstrated by individual mindsets and emotions. Actions or 
processes of the group members contribute to the development of levels of cohesion. The perception of group cohesion by members is a result of the activities and interactions between group members. One missing point is, while member actions and behaviors are necessary to begin creating levels of cohesion, a cycle develops in which levels of cohesion and member actions are intertwined, with each becoming predictive of the other. If group member interactions are positive at an early stage of development, that may generate more positive actions and behaviors within the group, which in turn increases group cohesion. The same process may hold true for negative early group interactions.

Other examinations of group cohesion treat it as an emergent state that develops over time and therefor definitions of cohesion vary depending upon its state of development at the time of study (Salas, Grossman, Hughes, \& Coultas, 2015). Chiocchio and Essiembre (2009) conducted a meta-analytic review to differentiate 33 cohesionperformance correlations. One of their inclusion criteria was that groups must have been organized for at least four weeks suggesting this was a minimum amount of time necessary for cohesion to develop enough for valid research on the topic. Emergent states, such as group cohesion, may require time to form and develop (Bradley, Baur, Bradford, \& Postlethwaite, 2013).

Cohesion as a construct lacks a universal definition and measurements of cohesion vary greatly (McLeod \& von Treuer, 2013). Group cohesion research has also treated cohesion as either a unidimensional or multidimensional construct. Unidimensional research defines cohesion by a single measurement such as attraction to a group or commitment to the group (McLeod \& von Treuer, 2013). Multidimensional 
research considers several variables when measuring group cohesion like trust, types of communication, and member personalities (Carron \& Brawley, 2000). Carron and Brawley (2012) recommend researchers bear in mind the research questions of the study when settling on a specific concept of cohesion. As stated previously, there is not a universal definition of the construct of cohesion and that requires researchers to specify the conceptual foundation of group cohesion being utilized.

This qualitative study used constructivist grounded theory as the research strategy. Grounded theory design develops a theory based on participant views (Creswell, 2014). This research strategy is appropriate to this study as the research questions explore how participants experience cohesion. Kathy Charmaz developed constructivist grounded theory which recognizes the social construction of reality (Rieger, 2018). Participant experiences and views regarding cohesion are subjective.

\section{Design of the Study}

\section{Setting}

The setting for this research was a specific doctoral program with a cohort consisting of virtual, partially distributed members at various locations throughout a single state. Although historically this doctoral program has allowed a few students who had already completed considerable coursework to continue participation using virtual communication technology, the program began the 2019 cohort with several members using virtual communication technology from anywhere in the world as the primary means of collaboration and program completion. Most of the cohort members using virtual communication technology were located within the United States and all cohort members must participate in person during the two summer sessions. 
This program comprises five satellite universities within the state all participating as part of a cooperative educational doctorate program with a maximum capacity of approximately 18 students per satellite cohort, or up to 90 students total. The entire cohort meets during two summers, four weeks each, for intense course and group project completion. The remaining courses are held at the satellite campuses. Many cohort members attend classes at the satellite campus located nearest them geographically. Some of the cohort members attend classes using virtual communication technology. For example, campus A may have 18 members overall with 12 members physically present in the classroom and 6 members using virtual communication technology as the means of attendance. In addition, these 18 members may be divided into smaller groups to complete course projects during a semester. These smaller groups may utilize virtual communication technology in the process of collaboration to finish the group project. The groups are virtual, partially distributed teams since some members attend in a traditional fashion face-to-face and others attend virtually.

\section{Participants}

All 90 cohort members were invited to participate. An invitation to participate was sent by email to all instructors and students (see Appendix A). Arrangements were made for the researcher, via virtual communication technology, to speak to students during a mid-semester session. At that time, the researcher again extended the invitation for student participation, gave a brief overview of the study, and answered questions. Those students who agreed to participate were sent an invitation via email to complete an online survey using Qualtrics. The goal was 8-12 co-located and 8-12 virtual students agreeing to the interview. 
Because participants were all members of the same cohort, they may have been known to one another and to instructors within the program. Responses of individual participants were kept confidential and known only to the researcher. Consent was explicit in order for respondents to participate in the survey and interview.

\section{Instruments}

A survey consent form (see Appendix B) and survey questions (see Appendix C) was be sent to participants via Qualtrics to gather demographic information, one question to briefly explore their emerging understanding of cohesion within their virtual, partially distributed cohort, and an item on whether they would agree to meet with the researcher for the interview portion of the study. In addition to basic demographic information, the survey asked about the participant's primary career field, such as elementary education or higher education, and years of experience in that field. The survey also asked about participant experience using virtual communication technology.

Interviews lasted approximately 20-30 minutes each and were conducted near the end of the Fall 2019 semester. A consent script was read by the researcher at the start of each interview (see Appendix D) at the end of which the participant was asked to verbally consent to continue with the interview. The interview questions (see Appendix E) asked about previous and current group cohesion experiences. Participants were asked to share a) experiences of group cohesion or lack of cohesion within their current doctoral cohort, b) experiences of group cohesion or lack of cohesion with a group outside of the doctoral cohort, c) thoughts about the essential factors affecting cohesion, and d) recommendations of way the doctoral program may be adjusted to better facilitate cohesion. The interviews were semi-structured. A semi-structured interview elicits 
specific information from respondents using a structured list of questions but allows for flexibility of the interviewer to use own discretion to respond to certain situations and responses during the interview (Merriam \& Tisdell, 2016). Some interviews were video and audio recorded while others only contain audio. This option allowed for accurate transcription of exact responses from participants (Merriam \& Tisdell, 2016).

\section{Methodology}

Grounded theory. Grounded theory was first introduced by Barney Glaser and Anselm Strauss in 1967 and its name comes from theory being grounded in the data (Merriam \& Tisdell, 2016). Theories emerge from the data and analysis rather than being stated prior to the gathering or analysis of data (Mertens, 2015). Hypotheses are generated using inductive reasoning during data analysis and those hypotheses can be verified through the further gathering and analysis of data (Salkind et al., 2010).

For exploring social processes lacking previous research grounded theory is a fitting method (Salkind, 2010). Virtual, partially distributed groups have not been studied thoroughly and the literature is sparse on this topic. It is also useful when other previously research theories are not a good fit due to unique situations (Creswell, 2012). This study explored the development of group cohesion and grounded theory is useful for discovering how a thing changes over time (Merriam \& Tisdell, 2016).

Because this method of inquiry requires systematic data collection and analysis, it is particularly useful for the novice researcher (Creswell, 2012). Grounded theory is a rigorous yet flexible approach (Salkind, 2010). The rigor is in the constant comparison of data, memo writing, coding, and categorization of data (Charmaz \& Belgrave, 2018). 
Constructivist grounded theory. One of the constructivist paradigm's

underlying assumptions is that reality is a social construct that is bound by situations and circumstances (Merriam \& Tisdell, 2016). Research using the constructivist grounded theory approach considers the circumstances and social conditions in which the research questions and participants reside (Charmaz, 2017a). It acknowledges the researcher as cocreator of knowledge along with participants (Rieger, 2018). The interactivity between the researcher and the data influences the researcher's choices of categories recognizing the researcher's beliefs and values (Creswell, 2012). There is an assumption that researcher's treatment of the data is influenced by the researchers own values, experiences, and perceptions (Charmaz \& Belgrave, 2018).

Constructivist grounded theory has four criteria for theory evaluation: creditability, originality, resonance, and usefulness (Rieger, 2018). Initial coding is followed by focused coding in which the researcher moves back and forth between the two in order to further analyze the codes and refine categories (Giles, de Lacey, \& MuirCochrane, 2016). This process of constant comparison is a basic analysis technique of grounded theory (Merriam \& Tisdell, 2016).

\section{Data Analysis}

Levels of analysis for the survey was at the individual level while interviews were analyzed at the individual and group levels. Survey data of demographics and experience were analyzed using descriptive analysis. Frequency distributions were applied to describe participant demographic, primary career field, years of experience and use of virtual communication technology responses. The survey item regarding the participant's definition of cohesion was analyzed using open coding. 
Interviews were transcribed by the researcher listening to the audio recording and typing each word into a template containing the questions. Interview data was analyzing using open coding content analysis to categorize responses.

Open coding is the preferred method of initial analysis for grounded theory research (Charmaz, 2017a). Coding organizes data into categories (Creswell, 2014). Initial coding will analyze the interview data distributing the responses into task cohesion and social cohesion categories. Because constructivist grounded theory is this study's theoretical lens, data analysis progressed to focused coding. Focused coding analyzes the initial open coding using frequency distributions of those codes to determine the codes that reappear most often (Rieger, 2018).

Constructivist grounded theory makes use of inductive-abductive logic. The researcher inductively analyzes the data to form a hypothesis then uses abductive reasoning to determine the most likely explanation (Rieger, 2018). This type of reasoning was most apt for this study because participant experiences are subjective. They cannot be proven or disproven; only interpreted using a best educated guess based on the inductive-abductive reasoning process.

To control for researcher bias, throughout data analysis, the researcher wrote memos to reflect thoughts on emerging themes, categories, and ideas (Giles et al., 2016). Memoing also assisted the researcher with maintaining checks on self-preconceived notions and biases regarding coding and categorization of participant responses. Researchers are cautioned to avoid applying predetermined ideas to the data and writing memos is an essential step to inhibit this possibility (Rieger, 2018). 


\section{Limitations}

There are several limitations needing acknowledgement. The first limitation regards transferability. This study was narrow in scope and sought only to gather data from students in a single doctoral program. In addition, this research only gathered data from students during one semester, although these groups continued for three more regular semesters and one more summer semester. Levels of cohesion measured during the remaining semesters may have different results. Few of those invited to take part in this study agreed to participate in both the survey and interview. It is worth noting that these students are not necessarily representative of the experiences of the greater cohort group.

Other limitations involve participant responses. First, interviews were not anonymous. It is possible that participants were not as open with responses as may be with another data gathering method that ensures participant anonymity. Fear that candid responses may adversely affect a participant's image or that those responses may be shared with others may have altered replies to interview questions.

Second, participant responses during the interviews were based on their perceptions of experiences which are open to bias, inaccuracies, and a lack of pertinent information. They may not have been privy to information that would allow them to have a more objective view of their experiences. Additionally, although participants were cautioned against discussing their own interview experiences and responses, it is possible that some chose to share with other participants. This sharing may or may not have affected other participant responses. 
Limitations concerning measurement is of note also. Exploration of task cohesion may be overstated in that all participants are pursuing an advanced degree. This suggests they already share a strong desire to complete given tasks or projects. Participants may have reported higher levels of task cohesion given the mandatory nature of completing a project with a group as a requirement for passing a course.

This research was qualitative, employing a brief survey and interviews for data collection. The quality of the study is highly dependent on the researcher's skills which reveals another limitation. To reduce the errors and possible personal bias of the researcher, interviews were recorded. Content analysis of interview data focused solely on verbiage. It did not account for body language, tone of voice, or facial expressions which respondents displayed to emphasize meaning in their replies. For example, a statement of "I really feel included in the group" was coded based on the verbiage regardless of a respondent's tone of voice or facial expression. Every effort was made with follow-up questions to mitigate such occurrences and gain clarity of respondent meaning.

Finally, this research did not account for other, outside influences on perceived group cohesion. It is acknowledged that factors outside the group may have influenced a participant's perception of cohesion. For instance, a life event precludes a member from group participation for a period of time and the member begins to feel they are an outsider once they are able to rejoin collaboration.

\section{Delimitations}

Delimitations are a necessary aspect of the research design. First, the scope of this study is narrow in that the only possible participants were current students in one 
particular doctoral program. It is limited to this program in part because it allowed the research to delve more deeply than would be possible with a larger group of participants. It also kept the results strictly related to this particular program and therefore more meaningful to program stakeholders. However, the results may be more widely useful for other such educational programs and possibly virtual, partially distributed team workgroups.

Second, all participants in this study have high levels of education and experience in working in groups professionally. Admittance to this doctoral program requires applicants to have a master's degree at a minimum. Most students were also working professionals while in the program.

Third, all cohort members were not participants. The interview method of data collection is cumbersome and time consuming. Non-participating cohort members' experiences were not recorded nor considered.

\section{Assumptions}

Some assumptions in this study involve participants. It is assumed that all participants were truly volunteering their involvement and were not coerced in any way. In addition, they answered interview questions honestly and candidly.

Other assumptions involve the doctoral program. It is assumed that all students admitted to the program met the minimum requirements of admission. In addition, students were not incentivized in any way to participate and that student group formation during the study period were not influenced by the anticipation of this research. 


\section{Definitions of Key Terms}

\section{Cohesion}

Group cohesion is defined as the individual member's feelings and attitudes toward other members and the group as a whole, sense of belonging, and commitment to the group and achievement of group goal(s). This definition of cohesion considers the possibility that, for specific types of groups, only certain aspects of cohesion are applicable (Mullen \& Cooper, 1994). Group purpose and goals, length of time group exists, group size, and cultural norms all play a role in an appropriate definition of cohesion (Mullen \& Cooper, 1994). For instance, smaller groups tend to experience higher levels of cohesion than larger groups (Šumanski, Kolenc, \& Markič). Carron and Brawley (2012) define cohesion as "a dynamic process that is reflected in the tendency for a group to stick together and remain united in the pursuit of its instrumental objectives and/or for the satisfaction of member affective needs" (p. 731). This definition does not consider the fact that some groups have few choices other than "sticking" together, at least until a particular goal is achieved. Military units must follow orders and remain within a group or risk punishment. Work group members' option may be to find other employment. Participants in this study varied regarding their input into group formation.

\section{Task and Social Cohesion}

This study considered both task and social cohesion constructs. Task cohesion refers to the commitment to achieving group goals (Forrester \& Tashchian, 2004). Task cohesion may be especially strong when a group is formed primarily for the completion of a task (McLeod \& von Treuer, 2013). Social cohesion concerns inter-group relationships like feelings, attitudes, and a sense of belonging (Carron \& Brawley, 2012). 
An example might be group member's wish to cultivate positive relationships with other group members (von Treuer, McLeod, Fuller-Tyszkiewicz, \& Scott, 2018).

\section{Emergence or Development of Cohesion}

The development of group cohesion is an emergent state. For this research, emergence of cohesion is a process that occurs as group members interact to complete a task (Kozlowski, Chao, Grand, Braun, \& Kuljanin, 2013). Groups may not experience cohesion in the same manner or levels throughout the duration of the group. There may be a drastic contrast between group cohesion measured at the beginning of group formation and again near the end of the group's existence. Marks et al. (2001) define emergent states concerning group cohesion as "constructs that characterize properties of the team that are typically dynamic in nature and vary as a function of team context, inputs, processes, and outcomes" (p. 357).

\section{Group Types}

Co-located. Groups whose members gather in a single physical location are considered co-located. This is also referred to as a traditional method for group meeting. Virtual groups. Virtual groups are those that conduct business using virtual communication technologies. Group members are not physically present in the same location with one another.

Virtual, partially distributed groups. In a virtual, partially distributed setting, group members interact virtually and face-to-face. This type of group consists of members who are co-located and others who are geographically dispersed (Eubanks et al., 2016). 


\section{Virtual Communication Technology}

Zoom was the virtual communication technology used for the geographically distributed cohort members. Zoom is a video conferencing Internet platform that enables users to participate in group meetings with features that support video and audio using a computers camera and microphone components. Other examples of virtual communication technologies include Skype and WebEx. Users may join by telephone, screen share, and group message, with the capacity to use many other collaboration tools. Document sharing formats such as Google Docs, SharePoint, and OneNote may be used to complete group projects. Outside of class meetings, collaboration on assigned group projects required both co-located and distributed group members to use some of these virtual communication technologies.

\section{Significance of the Study}

With the increase in widely available communication technologies, virtual groupwork is on the rise with expectations that it will continue to become more prevalent (Blair, 2015). Much research has been conducted regarding groups and group dynamics. This study contributes to prior research on group dynamics as members of the education doctorate cohort's reported on their experiences of cohesion.

Research has shown that group cohesion is an important aspect of group dynamics and performance (Carron \& Brawley, 2012). Exploring how an education doctorate cohort's members experience group cohesion adds to prior research on this topic. In addition, the study explored the linear development of group cohesion for the duration of a semester. 
Task cohesion is the level of unity of a group's efforts to achieve a common goal (Forrester \& Tashchian, 2004). The participants in this study were members of groups with specific objectives, with the primary goal being to complete assigned group projects successfully. Thus, groups were formed to complete a task. This research adds to the body of literature on task cohesion.

The level of motivation of group members to create and maintain social relationships within the group is social cohesion (Carless \& De Paola, 2000). Although participants in this research were placed in groups to complete a common task, social cohesion developed as group members interact. This research augments prior research in tracking the development of social cohesion as experienced by participants.

Virtual groups and virtual, partially distributed groups, how they function, and the role cohesion plays presents specific challenges above and beyond co-located groups. This empirical research study helps fill the gap in the theoretical literature on virtual, partially distributed groups. It is inaccurate to apply co-located group dynamics to virtual groups or the hybrid form of virtual, partially distributed groups. Although there may be some aspects that are similar with all three of these, there are some important differences that require research. Some of those distinctions involve questions such as, do the colocated members of virtual, partially distributed groups form closer social bonds, communicate more effectively, or have more influence on group decisions than those group members who are distributed and participate virtually. Other distinctions include whether the distributed group members feel included, whether their opinions are heard by the co-located members, and whether there is a perception of higher task and social power with the co-located group members. 
Using technology to deliver instruction is not new. Interactive Television (ITV) has been used by educators for many years. Groups that complete work strictly or primarily via virtual means has become more common. One of the differences between ITV and virtual groups working together to achieve goals is that segments of the ITV groups are co-located and can perform in a traditional manner while the virtual groups' members may be far-flung and never be present together geographically. This is an example of a virtual, partially distributed team. Studying these virtual, partially distributed groups is essential to determine best practices in educational delivery methods, most beneficial types of communication technology, and realistic expected outcomes.

Cohesion is vital to group success and performance (Paul et al., 2016). This research endeavored to discover the similarities and differences in the experiences of colocated students and those who participate using virtual communication technology related to group cohesion. Revealing these aspects can give stakeholders valuable information that can be used to make data driven decisions and plan for future program cohorts. Other educational institutions and instructors will benefit from the knowledge and data gathered to provide the appropriate curricula, allowing them to enhance, foster, and facilitate student success. It is through the process of design, launch, review, and remediate, which is a basic tenant of effective educational delivery, that this program can continue to progress and improve. This study can be used as part of a program review phase and contributes to the information and conversation concerning future cohorts.

Outside of academia, many companies are using virtual, partially distributed teams as part of the workforce (Eubanks et al. 2016). To compete globally, many 
companies have opted to use virtual, partially distributed teams in an effort to employ talented workers that would not otherwise be available due to their geographically dispersed nature (Tzabbar \& Baburaj, 2018). Research on virtual, partially distributed groups working to collaborate and successfully complete projects would be helpful to these types of companies. This is especially true given the strong links between group success and cohesion, which is a focus of this study. 
SECTION TWO:

PRACTIONER SETTING FOR THE STUDY 


\section{Introduction}

The research questions in this study involve an educational cohort so the setting is an educational institution. The institution is a large university located in a midwestern state. Founded in the 1830 's, the university houses several colleges:

- College of Agriculture, Food \& Natural Resources

- College of Arts \& Science

- College of Business

- College of Education

- College of Engineering

- School of Health Professions

- College of Human Environmental Sciences

- School of Journalism

- School of Law

- School of Medicine

- College of Veterinary Medicine

Average annual enrollment is more than 30,000 with over 13,000 full-time faculty and staff, and well over 300,00 alumni. Given its establishment nearly 190 years ago, it has a rich history and is well known throughout the country.

\section{History}

This educational institution was the first public university west of the Mississippi River and in the Louisiana Purchase Territory. A deciding factor in its location was nearness to the main transportation and commerce routes of the state. Twice during its history efforts were made to move the university. During the Civil War, a group wanted it 
moved to an area within the state with more support for the Union. Later, during the development of the College of Agriculture and what is now the College of Engineering, another push to move the entire university was launched. As a compromise, a School of Mines and Metallurgy was created and located at elsewhere within the state (University Source, 2003).

As the university grew, it became a member of the Association of American Universities which was an organization of top graduate and research institutions. In the 1960's the university expanded and implemented a four-campus system; the original campus, the one created for the School of Mines and Metallurgy, and two others located in the largest cities in the state. Authority and responsibility for the university system resides with the University Board of Curators and President with a Chancellor controlling each campus (University Source, 2003).

Other firsts include the first course in civil engineering west of the Mississippi River and the world's first journalism school. The university became a center for agricultural research and added schools of law and medicine. It's college of veterinary medicine was established in the 1880's adding a Doctor of Veterinary Medicine in the 1940's. The college of education was founded in the 1860's to prepare teachers and is now a leader in teacher preparation (University Source, 2003).

\section{College of Education}

The university's first president requested the creation and funding of a professorship specifically to prepare teachers. Due to a lack of funding, the position remained open for more than ten years. The state general assembly passed legislation in 
1855 requiring the establishment of a primary school to prepare students to enter the university (University Source, 2003).

The College of Normal Instruction was established in 1867. The college's name stemmed from the term "normal instruction" being commonly used as teacher preparation schools created standard or norms for teaching. Four male students enrolled in the college for the first year and none went on to pursue teaching. The first females admitted to the university, 22 in all, were enrolled in Normal College. Three departments of the college were established; the normal school for instructing and training teachers, a school for preparing student to enter the university, and a school to demonstrate teaching students from the normal school. The primary school was ended in 1877 but each academic department continued student preparatory work until 1894. By then, the increase in state accredited high schools prepared students to enter the university (University Source, 2019). After several name changes, the College of Normal Instruction finally became known as the College of Education in 1947 and departments were created in 1968. They were as follows:

- School of Information Science and Learning Technologies

- Department of Curriculum and Instruction

- Department of Educational Counseling Psychology

- Department of Health and Exercise Science

- Department of Educational Administration

- Department of Educational Leadership and Policy Analysis

- Department of Technical and Vocational Education

- Department of Industrial Education 
- Department of Special Education

- Department of Secondary Education

- University Laboratory School

- Phi Delta Kappa, Gamma Chapter

\section{Organizational Analysis}

Organizations can be viewed and analyzed in multiple ways. One example is the Four-Frame Model by Bolman and Deal (2013). Their framework merged major organizational theories into four points of view, or frames, through which organizations can be analyzed. The four frames are structural, human resource, political, and symbolic. All organizations can be assessed using these four perspectives.

The structural frame has several assumptions. Organizations have goals and dividing labor with specialization increases the likelihood of achieving those goals. The division of labor is controlled and coordinated by the organization so that work is effectively interconnected. The contradiction between division and specialization of labor and maintaining central control must be reconciled within each organization based on goals, current technology, strategy, and circumstances. Organizational structure is the plan outlining expectations for organizational authority, policies, and procedures.

The university's organizational structure is representative of Mintzberg's Professional Bureaucracy configuration (Bolman \& Deal, 2013). Highly educated professionals occupying various levels of professorship and leadership roles make up the operating core. The strategic apex of the organization includes the chancellor and provost while deans of the numerous colleges form the middle line. 
Within each college exists a sub-organizational structure, deans being the strategic apex, directors and department chairs the middle line, and educators the operating core. The statewide cooperative EdD program has an associate director located at the host university's campus and each of the remaining four satellite university locations has a liaison responsible for coordinating the program on-site.

The university's existence is to achieve the goals of providing educational opportunities and further various research initiatives. The structure is divided into specialized areas such as the various colleges and labor is distributed appropriately throughout. Organization wide policies, procedures, requirements, and guidelines are in place to ensure coordination and consistency throughout the sundry departments and individuals.

The Human Resource Frame (Bolman \& Deal, 2013) expects that "organizations exist to serve human needs rather than the converse" (p.117). The relationship between organizations and people is reciprocal since organizations need people's talent and abilities while people need jobs and incomes. The right fit between an organization and its employees benefits both.

This educational institution's mission statement testifies to the organizations commitment to serve human needs. It is committed to public service and the responsibility to generate and distribute knowledge by facilitating teacher and student collaboration. Along with a mission statement is a statement of values. First is respect for self and others leading to open and honest discourse and appreciation of differences. The value of responsibility is the careful consideration of decisions and consequences as well as being careful caretakers of resources. Discovery is a value that entails the support of 
the process of learning and the knowledge gained. Finally, excellence is a standard the university is committed to pursue diligently.

The university has many colleges requiring people with specific talents and abilities in a variety of areas. This is in addition to the many support staff in areas such as environmental maintenance, record keeping, clerical, and safety. The university is the largest employer in the area (Regional Economic Development Inc., 2017-18). It employs over 3,000 faculty members and 13,800 staff members.

Basic human resource strategies include hiring the right people, employee retention which includes investing and empowering them, and promoting diversity (Bolman \& Deal, 2013). The Columbia Daily Tribune published a 2017 report on the university's salaries compared to other public members within the American Association of Universities. Average compensation for faculty was lower than all of the other 33 public university members. The only exception was for men holding full professorships and only the University of Oregon paid less. The pay gap is worse for women holding full professorships both in comparison to other association members and within the university itself. Their average salary was $\$ 30,000$ below comparable positions held by women at other schools. Within the university, women holding full professorships made 83 cents for every dollar a man with a full professorship earned. A campus climate survey in 2016 showed that for faculty and staff compensation was the largest complaint.

One way the university does invest in faculty and staff is through their educational assistance benefit. Eligible employees taking 6 or fewer hours per semester can have seventy-five percent of the tuition and fees waived. In recent years there has been a concerted effort to ensure diversity and inclusion within the university for faculty, 
staff, and students. In 2016 the university created the Division of Inclusion, Diversity, and Equity (Joyce, 2016). The divisions Inclusive Excellence Framework provides a clear outline with objectives and actions the university strives to uphold. Progress is measured via a campus climate survey, the last one being given in 2016.

Another of Bolman and Deals (2013) perspectives is the political frame. The political frame assumes organizations are made up of various people and groups who form coalitions based on commonly held values, ideologies, interests, and points of views. Because resources are scarce, there is great power in deciding who gets what and this can pit coalitions against one another. Compromises are made through negotiation.

The university is divided into various colleges which naturally creates various groups who must jockey for the scarce resources. In addition, there are other groups competing for funds, facilities, and attention such as athletic programs, health and wellness programs, and campus law enforcement. Decisions regarding distribution of resources is a complex and complicated multi-layer process. The primary sources of funding for the university are tuition and fees and state appropriations (University Source, 2019). The overall budget is directed by campus strategic plans and decisions of the President and Board of Curators regarding policy. Budget development is a process that goes through many drafts with multiple changes, many due to the negotiations of the many group stakeholders. In all, over 200 college and school divisions that include more than 1,100 departments and nearly 30,000 cost centers all represented by about 500 individuals collaborate to create a single fiscal year's budget (University Source, 2019).

Those 500 people have position and reward powers over the budget because they have the authority to make fiscal decisions in awarding funding (French \& Raven, 2005). 
It is possible that within the larger group making decisions about budget items are individuals forming coalitions on the basis of reciprocity wherein they agree to help one another get what they want. Partisan power resides with the various interest groups such as the colleges and athletic departments who create coalitions in an effort to get their programs the most funding (Bolman \& Deal, 2013).

The last of the four frames is the symbolic frame. The ideas behind this frame involve the culture and symbols of an organization. Organizational culture can define and distinguish it from other organizations through symbols, rituals, and traditions (Bolman $\&$ Deal, 2013). The symbols, rituals, and traditions also create a bond that adheres the organization and stakeholders together.

Similar to other educational institutions, this university has a mascot, school colors, and a logo that is unique to the institution. One symbol of the university is The Columns. The Academic Hall was destroyed by fire in 1892 and the columns are all that remain and serve as a symbol of strength. The freshman and senior classes have traditional rituals involving The Columns. The incoming freshman class gathers and walks through The Columns to symbolize the start of their experiences at the university. In a similar ritual, the graduating senior class gathers and walks through The Columns symbolizing the connection they will continue to have with the university as alumni. Memorial Union tower, built in 1926, is a tribute to 116 university students who died in World War II. Peace Park, a section of MacAlester Park, was dedicated after the shootings at Kent State University. Both are symbolic tributes to those lost in tragedies. 


\section{Leadership Analysis}

Within the College of Education, the university offers a Doctor of Education degree $(E d D)$ though a statewide cooperative. This program operates in partnership with 5 universities across the state. Launched in 1997, it offers coursework at the various cooperating universities making it geographically available to qualifying applicants (unpublished document). The excellent reputation of the program is supported by a graduation rate of $88 \%$ and $97 \%$ of EdD students surveyed said they would definitely recommend the program to prospective applicants (Student Handbook, 2017).

A department chair provides overall guidance for all programs and faculty within the department. The statewide cooperative program is led by a director and an associate director/program coordinator. Participating institutions each have a site coordinator responsible for facilitating student progress within the program and program coordination for their respective campus. A coordinating committee is comprised of two representatives from each participating institution. Committee responsibilities include program facilitation, policy setting, applicant selection, and assurance of the program's high-quality curriculum and ongoing improvement. Faculty from all participating universities collaborate as program instructors and advisors (Student Handbook, 2017).

Rather than focusing leadership analysis on individuals, examination is better accomplished by evaluating the actions of the program's leadership using a complexity leadership framework. Viewing the leadership through an action lens highlights the many behaviors, decisions, and activities of various leaders within the statewide program that have contributed to its growth and success. Complexity Leadership Theory's framework has three basic perspectives: adaptive, administrative, and enabling or action-centered 
(Brown, 2011; Baltaci \& Balci, 2017). Analysis will also include how servant leadership is demonstrated at all levels of program administration. Although some of the individual leaders have changed over the course of this program, the core values and mission remain.

Adaptive leadership covers situational challenges, leader actions, and adaptive work (Northouse, 2016). Leaders evaluate a challenging situation, determines a course of action, and then does the adaptive work necessary for resolution. Leaders of the statewide cooperative have faced many challenging situations since the program's inception. One such challenge is the constant change in technology, computer and software programs, and internet capabilities. Recently, the statewide cooperative leadership has opened program participation to allow students the ability to use video communication technology to attend classes and collaborate with other students. During the required gathering of students at the university to participate in the summer session, on-site leaders encounter technology challenges. Internet bandwidth is sometimes taxed beyond capacity and quick decisions must be made to remedy the situation.

The focus for administrative leadership is on activities that pertain to program organization, delegation of duties, and providing resources to successfully achieve organizational goals (Baltaci \& Balci, 2017). With the first memorandum of understanding in 1997 began the commitment to "continued work on the refinement and implementation of the program" (unpublished document). The program has continued to improve and grow under the guidance of innovative leadership. Leaders improved the application and admissions process. The statewide cooperative program leaders coordinate coursework at 5 separate sites within the state. Each satellite campus has a 
program coordinator responsible for carrying out program initiatives, delegating advisor responsibilities to on-site faculty, and ensuring adequate resources such as classroom facilities and appropriate technologies, are available and operational.

Enabling or action-centered leadership can be viewed as facilitator or mediator between administrative leadership directives and restrictions and adaptive leaderships need to adjust and solve challenging situations (Baltaci \& Balci, 2017). Statewide cooperative campus coordinators may fit the role of enabling leadership at times. The overall program and each campus have specific policies, requirements, and guidelines that must be followed. Individual instructors, student advisors, and students may have unmet needs, requests, or questions that must be handled through appropriate channels with administrative leadership. Campus program coordinators act to solve issues and serve as the go-between.

The statewide cooperative program is guided by educators interested in growing and developing leaders in education. The ultimate goal is that every student within the program graduate with a Doctor of Education degree, but expectations within the program and from the educational leadership are high. Although graduation is the goal, the leadership has not lowered standards to inflate graduation numbers. All stakeholders have shown an altruistic interest in holding students and the program itself to high standards. A degree earned through this program has high merit and is recognized within academia as stellar.

Servant leadership is demonstrated by listening, empathy, stewardship, and commitment to growth of the people (Northouse, 2015). One of the leadership decisions to improve the quality of instruction was to create an ethics and diversity course. Leaders 
listened to former students who requested this addition. This demonstrates the commitment to improvement and authentic desire to make sure the program is appealing to a wider audience. Throughout coursework, the topics of diversity and ethics is constant. All leaders within the program have completed doctorate degree having completed coursework and successfully defended dissertations. They empathize with students in the program and students reap the benefits of leader experiences. Leaders within the program have stewardship of it and responsibly serve in its best interest. In addition, each student has an advisor who is a leader in the program to help ensure student success.

The commitment to continuous improvement is also a commitment to continuous change. Although improvement is positive, it is still altering some aspect of what or how something used to be. Kotter (2011) advocates for creating a sense of urgency to begin the change process. The statewide cooperative program operates within the realm of higher education in which change is a slow occurrence. Bolman and Gallos (2011) list the Three P's of Change: patience, persistence, and process. Leaders of the program prove they understand this with every new decision or alteration to any part of the program. Change can be particularly difficult to enact when things appear to be working fine (Hemp \& Stewart, 2011). Leaderships promises of continued program improvement is not dependent upon a set benchmark that, when reached, signals the program has reached its apex and can no longer progress.

Finally, the dissertation portion of this program does not promote research for the sake of scholarship only. There is a connection between the practices of leadership and theoretical knowledge (Schultz, 2010). The generation of knowledge throughout 
coursework and within dissertation research is also focused on the practitioner. There is an emphasis on how knowledge gained can be put to practical use by the student and others.

\section{Implications for Research in Practitioner Setting}

The statewide cooperative Doctor of Education program has been very successful since its inception in 1997. There have been many changes and improvements to the program over the years. With the incoming cohort, another change will be the ability for some students to participate using virtual communication technology. This research is intended to study one aspect related to this change: how the co-located and virtual participants experience group cohesion..

A consistent theme throughout the program is teamwork and collaboration. Prior to the first summer session, all students take an assessment to discover areas of strength. The results are used by program administrators to place students in groups so that each group consists of members with a variety of strengths. Groups are assigned a problembased project. The first summer session includes Team Building and Group Dynamics, a course covering group development, team building and performance, and problem-based learning as a team process. When the satellite cohorts convene for fall and spring semesters, the teamwork theme continues with instructor-assigned group formation to complete projects related to the specific semester's coursework. Cohesion is a key element of group dynamics and is essential for these groups to successfully execute the tasks of project completion.

Potential complications included a lack of participants, participant dropouts, and coordinating initial Zoom meetings with each satellite campus introducing the study. 
Research participation was voluntary for the cohort members so there was no guarantee of a suitable number of respondents to provide valid data. These students were exceedingly busy with coursework and some may have decided they did not have the time or energy. Some may have initially chosen to participate and then discovered they no longer had time or interest. Instructors at the various campuses may not have welcomed the inconvenience of allotting time for the researcher to provide information to potential participants.

There were potential opportunities regarding the results of data analysis. First, this research provides a baseline for measurement of an essential group dynamic, cohesion, for the program. Cohesion has been shown repeatedly to affect group and individual performance. Leaders in this program want students to succeed and this research provides valuable insight into student achievement with the implementation of the change to virtual student participation. A limitation is that this was a new cohort whose members were not as familiar with one another as they will become as they complete coursework in following semesters. The results may not be extrapolated beyond the first semester.

After the results and implications for practice are disseminated to the programs leadership, discussions may ensue involving the validity of the research or how it can be used to further improve the program. If results indicate students using Zoom to complete coursework and collaborate experience less cohesion than their co-located peers, leadership must decide how this impacts student success and overall experience within the program. Another point of discussion is whether to continue allowing students to participate in the program virtually. If results indicate little difference between students completing coursework virtually and co-located students, discussions may involve the 
possibility of expanding the number of students allowed to participate virtually in future cohorts. Another outcome may be that leaders want a follow-up study in a semester occurring later in the program or in a future cohort. One last possibility is that program leadership will appreciate the recommendations but decline to act on any recommendations.

\section{Summary}

The university has a long and honorable history and is well respected throughout the country. The organization has a typical structure as compared with other large educational institutions with an overall executive leader and leaders within each of the university's colleges. The organizational analysis viewed university through the fourframe model of structure, human resource, political, and symbolic (Bolman \& Deal, 2013). Leadership was analyzed using the Complexity Leadership Theory and servant leadership.

Being the first university west of the Mississippi River, the history is full of ups and downs as it laid its foundational roots. It weathered early political upheavals and the unsettled nature of the state during the Civil War. Throughout, the university's mission to provide educational opportunities has endured. From the first college of education the range of colleges and degrees has expanded to include journalism, engineering, medicine, and law, to name a few. The university has undergone inclusion changes as well. Only admitting white males initially, the institution began admitting females, then, adapting to changing social norms and societal pressures now has diversity as part of the mission statement and created a Division of Inclusion, Diversity, and Equity. 
Organizational analysis using the structural frame identifies the university's structure as similar to many higher educational institutions and exemplifies Mintzberg's Professional Bureaucracy configuration (Bolman \& Deal, 2013). The university was established to meet the needs of people which is a main assumption of the human resource frame. The relationship between the university and the individuals associated with it is reciprocal. It is the largest employer in the area providing many with incomes. Politically, the university has many coalitions in the form of colleges, interest groups, faculty, staff, and students vying for scarce resources. The main scarce resource is money in the form of funding allotted for the various groups. Power resides with both those in charge of making fiscal decisions and in partisan groups with varying levels of influence. Accompanying the university's rich history is the culture that has been created during its existence. Through the symbolic frame, analysis reveals an assortment of rituals, traditions, and symbols unique to the institution.

The statewide cooperative programs leadership includes a department chair, program director and associate director, campus coordinators, faculty, and program committee. Complexity leadership theory is applicable to leadership analysis. Adaptive leadership is evident as situational challenges arise and the statewide cooperative leaders strive to find solutions and adjust accordingly. Organizing, assigning authority and duties, and creating policies and guidelines represent administrative leadership. Action-centered leadership allowed for the challenges faced by leaders to be addressed and solutions created with consideration to the responsibilities of the adaptive leaders. Overall, the programs leadership is servant leadership. From the university department chair to the faculty at each satellite campus, leaders of the program have as a main goal the successful 
completion of an exemplary doctoral program by students. They listen to student suggestions for program improvement and expansion, empathize with the struggles of the students, create the sense of community within the cohorts, and provide responsible stewardship.

Implications for this research are comprised of both potential challenges and opportunities. Challenges include a lack of respondent participation due to student work overload time constraints. Teamwork and group collaboration are central themes throughout the program, so the construct of group cohesion is important to individual, group, and program success. There is the potential for leadership to use this valuable research in future decision-making regarding student program participation using virtual communication technology. 
SECTION THREE:

SCHOLARLY REVIEW FOR THE STUDY 


\section{Introduction}

In exploring how virtual and co-located group members experience cohesion it is crucial to delve into the various ways group cohesion has been studied and addressed. Although this study focused on task and social cohesion and how it may change over the duration of a group's existence, surveying the construct and various definitions of cohesion presented in the literature provides a solid foundation for the conceptual framework of this research.

There are three types of groups when considering member location. Co-located groups have members who meet and work or collaborate in the same physical space. This is also known as a traditional group. Virtual groups are made up of members who are geographically distributed. They use virtual communication technology to communicate, share ideas, and collaborate. The group members may never meet face-to-face. Virtual, partially distributed groups are comprised of members who are both co-located and geographically distributed. Essentially, some of the members meet, work, and collaborate in the same physical space while other members use virtual communication technology to meet, work, and collaborate with the rest of the group. The co-located group members must also use communication technology so they may communicate with the distributed members of the group.

\section{Co-located Group Cohesion}

Co-located group cohesion has been a well-researched concept in the last 50 years (Greer, 2012). In studies researching small groups, the most significant factor has been cohesion (Carron \& Brawley, 2000). A major problem with the concept of group 
cohesion is there has been no agreed upon comprehensive definition. Literature reviews reveal various descriptions and definitions of cohesion (McLeod \& von Treuer, 2013).

Definitions of group cohesion have evolved, and many group cohesion studies reference early definitions. Festinger (1950, p. 274) defined cohesion as the "resultant of all the forces acting on members to remain in the group." Gross and Martin (1952, p.553) simplified a definition of cohesion as "the resistance of the group to disruptive forces." Later definitions narrowed, becoming more specific and include variables. For example, group cohesion is determined by members acceptance of shared goals and the level of unity among members to achieve the goals (Shiue, Chiu, \& Chang, 2010).

\section{Virtual Group Cohesion}

Some researchers have looked at the components of virtual group cohesion (Breuer, Hüffmeier, \& Hertel, 2016) or how virtual group cohesion impacts performance (Paul et al., 2016). As with co-located group cohesion, communication and trust are important factors influencing levels of cohesion in virtual groups (Thiss, 2017). Studies involving groups using virtual communication technologies to complete projects or accomplish goals concentrate on communication and communication technologies, trust, performance, and cohesion with most attempting to show connections between two or more of these aspects.

Communication is a key component of group processes because it is through communication that groups collaborate, solve issues, make decisions, and share knowledge. Group communication is defined as the sharing of information between group members (González-Romá \& Hernández, 2014). The quality, content, and 
frequency of communication are frequently the focus of research. Quality and content of communication is far more important than frequency (Marlow at al., 2017).

Several issues arise when communication is lacking in virtual groups. Group members are not in sync regarding work flow, goals, or current status of a project and may be duplicating or neglecting tasks. This can add monetary costs to a project and cause a project to miss completion benchmarks or deadlines. Lack of communication can also lead to misunderstandings and mistrust within the group (Reed \& Knight, 2009).

More is not always better when considering group communication. Groups with members who are familiar with one another may have a shared understanding enabling the group to perform tasks effectively with less communication than groups with members who are unfamiliar to each other. Quality and content of communication is important regardless of group member familiarity. Quality communication is clear, specific, organized, and does not contain irrelevant information (Marlow et al., 2017).

The types and amount of communication for virtual groups are dependent upon many factors, one of which is the stage of group and project development. Haines (2014) found that the amount of communication, and details contained therein, were higher at the initial stages of group and project development. After determining group structure, goals, task assignments, and roles, groups tended to simply complete individual tasks, decreasing the amount of communication.

Knowledge sharing is an important aspect of group communication. The exchange of ideas and knowledge is critical for group collaboration (Alsharo, Gregg, \& Ramirez, 2017). Distribution of prior knowledge and sharing newly gained information within the group are ways of sharing knowledge. Types of knowledge might include 
facts, skills, understanding, prior experience, or information. For virtual groups, this sharing may take place via e-mail, instant messaging, or video conferencing. Similar to traditional face-to-face collaboration, group members must respond to communications and participate during video conferencing (Rosen, Furst, \& Blackburn, 2007). Failure to do so may impact group cohesion. Sharing knowledge and information fosters important features of group cohesion such as trust and group satisfaction (Mesmer-Magnus, DeChurch, Jimenez-Rodriquez, Wildman, \& Shuffler, 2011).

One particularly interesting study looked at virtual group members who enjoyed a majority opinion on a particular item versus those members sharing a minority opinion. Swaab, Phillips, and Marlow (2016) presented groups of participants with the ability to have secret communication among members and other groups without that ability. Those majority-opinioned members in groups with the possibility of secret communication were more likely to listen and consider minority-opinioned members thoughts and ideas.

The use of technology to communicate with virtual group members is the focus of some studies. Schulze, Schultze, West, and Krumm (2017) studied the differences between face-to-face and computer-mediated communication among virtual group members regarding knowledge, abilities, skills, and other characteristics (KSAO). They suggested that the KSAOs differ most in the area of the knowledge and use of communication technology which are necessary for virtual group members.

\section{Virtual, Partially Distributed Group Cohesion}

The participants in this study are members of a virtual, partially distributed cohort. Membership in virtual, partially distributed groups comprise both co-located and virtual participants. The research and interview questions inquire about the experience of 
cohesion of both co-located and virtual group members. As in other group research, studies involving virtual, partially distributed groups center primarily on communication, trust, performance, leadership, and technology. Communication, trust, performance, and leadership are of great concern, regardless of the type of group, because each area plays a significant role in group dynamics (English, 2017). The technology aspect is especially important for these groups since the primary means of communication and collaboration occurs via virtual communication technology. Group cohesion is linked to group and individual performance and success (Susskind \& Odom-Reed, 2019). Levels of group cohesion are directly impacted by communication, trust, leadership, and technology (Haines, 2014; Paul et al., 2016; von Treuer et al., 2013)

Few studies on virtual, partially distributed groups have been published making it difficult to adequately address in a literature review. Research focuses on co-located groups or geographically dispersed groups with no members meeting face-to-face. Many of the studies regarding virtual teams previously covered in this section are somewhat applicable to virtual, partially distributed groups. The research on virtual groups and communication, trust, performance, leadership, and technology may apply to the virtual members of virtual, partially distributed groups. However, they are not specific to the hybrid nature of virtual, partially distributed groups and there are some studies that do apply specifically to those groups with a mixture of co-located and virtual communicating members.

A few studies of virtual, partially distributed groups or partially distributed groups examine group cohesion. Relating to the temporal nature of the development of group cohesion, a study by Susskind and Odom-Reed (2019) found that participants reported 
higher levels of team cohesion during the final phase of project completion. They also found that group member performance increased as member perceptions of cohesion grew.

Other studies offer findings that suggest ways in which dispersed groups achieve cohesion. Group members who are willing to share personal life stories and information engender interpersonal feelings of familiarity thereby increasing cohesion (Chiu \& Staples, 2013). Groups can also enhance cohesion by developing a social identity around the project. Petter and Carter (2017) also found that the development of subgroups can lead to conflicts within the group. This may be a concern with virtual, partially distributed groups in that the co-located members may form such a subgroup leaving the virtual group members feeling left out. This would have a negative impact on group cohesion in general and the co-located and virtual members' perceptions of cohesion may vary greatly.

To develop and maintain trust between partially distributed group members, Willis (2010) suggests an initial meeting between members in a co-located site followed by periodic face-to-face meetings. Cogliser (2012) connected trust and performance; when group members trust one another, it boosts group performance. Communication plays a large role in the development of trust. A lack of or lower quality of information about the distributed group members can lead to misunderstandings and incorrect perceptions thus restricting trust development (Trainer \& Redmiles, 2018).

An interesting study considered the impact of communication type (voice and text) and time delay on performance. Fischer and Mosier (2014) replicated communication delays experienced during space missions to discover the impact on 
group performance. One interesting find is that voice-assigned teams had to remember verbal conversations whereas those using text as their communication format were able to refer to the text when in doubt. The implication relevant to this study is that written communication allows for group members of virtual, partially distributed groups to refer back to conversational text rather than having to remember a one that occurred verbally.

Eisenberg, Post, and DiTomaso (2019) found links between transformational leadership of geographically dispersed teams and team communication and performance. The higher the geographic dispersion of group members, the lower the leader's influence on communication and performance. As distance increases, communication decreases. The distance may interfere with the dispersed members seeing the leader as authentic. Lacking the social nuances, such as tone of voice, body language, and facial expressions, that are more apparent in face-to-face communication, even true transformational leaders may have to make extra efforts to convey their goals to dispersed group members.

\section{Communication Technology}

Virtual communication technology includes e-mail, instant messaging applications or software, and video and audio conferencing (Schaefer \& Erskine, 2012). Other methods of sharing information or documents include document storing and sharing platforms such as Google Docs and Microsoft's SharePoint and OneDrive. These types of document sharing platforms allow for virtual communication since group members with access can edit documents and insert comments within the documents.

A study by Laitenen and Valo (2018) looked at the meanings of communication technology in virtual group meetings. They found four frame categories: practical, work, user, and relational. The practical frame refers to the communication technology 
properties and capabilities. The ways the communication technology is used to communicate and allow employees to work is the work frame. User frame involves the interaction between the user and the technology. The relational frame comprises the use of communication technology to build relationships and share a space even when geographically dispersed.

Using communication technology allows for collaboration between group members to complete work. Building relationships through the use of communication technology can be more difficult. The complexity of communication involves much more than words. Non-verbal communication such as body language, facial expression, tone of voice, verbal inflection, gestures, and even clothing choices convey messages. One workaround for the inability to express relationship gestures physically, such as facial expressions or physical contact, is the use of emoticons. Emoticons are images that either overtly depict an emotion such as a smiling face or represent an emotion or idea using a symbolic representation such as a dove or rainbow (Jibril \& Abdullah, 2013).

A study examined the effects of face-to-face, desktop video conferencing, and text-based chat on virtual group interaction styles and outcomes (Hambley, O’Neill, \& Kline, 2007). Although the mean interaction score was higher in face-to-face than video conferencing and chat, Hambley et al. (2007) found that communication media richness did not impact task performance. In addition, Bradley, Baur, Banford, and Postlethwaite (2013) suggest that lower information richness helps to mediate a group member's negativity, limiting its effect on other members and possibly preventing its spread.

The transfer of implicit knowledge is more difficult using virtual communication technology. Implicit, or tacit, knowledge is gained by personal experience rather than by 
reading a book or instructions. It may be referred to as "know-how" and is usually achieved through years of practice or experience (Nonaka, I, 2008). This type of knowledge is a challenge to share with others when the parties involved are co-located. It is more difficult when the only means of communication is virtual (Reed \& Knight, 2009).

Paul et al. (2016) conducted a study on global virtual groups investigating the roles trust and cohesion play in coordination effectiveness and group performance. Similar to co-located group members, levels of virtual group trust and cohesion have a large effect on group performance. In addition, they found that part of a project's coordination should include a face-to-face initial meeting between members if possible. If not, there should be an "intentional socialization phase" (Paul et al., 2016, p. 196). The establishment of practices and procedures, role clarification, task assignment, goals, and other expectations early in the project was also suggested to create boundaries and guidelines and prevent confusion or misconceptions that may lead to mistrust.

\section{Task and Social Cohesion}

As definitions of group cohesion evolved, a common division of cohesion into two types, task and social, emerged (Carless \& De Paola, 2000; Eys \& Carron, 2001; Mason \& Griffin, 2003; Salas, et al., 2015). Cohesion has been identified as an integral part of group dynamics (McLeod \& von Treuer, 2013), has been studied to determine its effect on group performance (Eys \& Carron, 2001) usually studying task cohesion over social cohesion when researching group achievement (Carless \& De Paola, 2000). Task cohesion is the level of group commitment to accomplishing a task or goal (Carless \& De Paola, 2000). Social cohesion refers to the bonds, such as friendship and compatibility, 
within a group based on social relationships (Mason \& Griffin, 2003). The early

definitions with verbiage like "forces acting on members" (Festinger, 1950, p.274) and "resistance to disruptive forces" (Gross and Martin, 1952, p. 553) appear to fall into the current social cohesion category.

As social and task cohesion are concepts directly related to the research questions, prior research on these is especially important. Research participants were grouped and given a specific predetermined project or task. Because they had the same goal of successful completion of the project, task cohesion was a given. However, how the groups decided to achieve the task or project may have put them at odds. This may have had a direct impact on the levels of social cohesion within the groups.

\section{Development of Cohesion}

Group members do not instantly form cohesive bonds with one another, rather groups grow in stages. Ito and Brotheridge (2008) researched four stages a group progresses through: forming, storming, norming, and performing. Group creation occurs during the forming stage. The storming stage refers to group conflict, sometimes as members express opinions, adjust to one another's communication and work style, and members assert power. The norming stage happens as compromises and agreements are reached. Performance is the final stage when group members are familiar with one another, have accepted and behave within the agreed upon norms, and are able to focus more completely on the accomplishment of group objectives (Bonebright, 2010). Future group cohesion is however dependent upon the groups handling of a previous stage of growth. 
A concern with the construct of group cohesion is the linear nature of the development of group cohesion and cohesion as an emergent state (Gilson et al., 2014). While interaction occurs among members, cohesion is a possible outcome (Salas, Grossman, et al., 2015). Kozlowski (2015) suggests groups develop in stages; group formation, task compilation, and role compilation. Acknowledging group cohesion as an emergent state requires recognition that it is a process that may be erratic and dependent upon variables, such as, changes in group membership, tasks, assigned roles, or goals (Kozlowski et al., 2016). Measuring the stages of development of group cohesion entails longitudinal studies which restricts many researchers who have logistical, temporal, or financial constraints (Salas, et al., 2015).

Where a group is concerned, there must be a level of cohesion (Carron \& Brawley, 2012). Arguing that the definition of cohesion used in a study directly affects the research outcome, Carron and Brawley (2012) offer their own definition. Cohesion is "a dynamic process that is reflected in the tendency for a group to stick together and remain united in the pursuit of its instrumental objectives and/or for the satisfaction of member affective needs" (Carron \& Brawley, 2012, p. 731). Although much of their research is centered in athletics such as sports groups or fitness groups, they suggest specific procedures based on the context of a group are necessary to effectively assess cohesion. One issue with Carron and Brawley's (2012) definition of cohesion is that is does not account for groups who have little choice in sticking together to achieve a goal. Participants in this study would have had to be willing to accept a failing grade or even drop from the program if they refused to stick together to complete their assigned project. 
In a study conducted by Haines (2014), the levels of a sense of belonging in virtual groups was linked to three findings. Group members should have well-defined goals, be required to communicate with one another, and have the idea that they may have to work with one or more of the other group members at some time in the future.

The development of cohesion in virtual groups is partially determined by each member's willingness to interact with others by reading and replying to e-mails and participate in online or virtual meeting discussions (Gaylon, Heaton, Best, \& Williams, 2016). This is similar to co-located groups in that members must converse and participate in meetings to facilitate the development of group cohesion.

Trust.Trust in virtual groups is another area of study, most focusing on the levels of trust in virtual groups and strategies to build trust. Alsharo, Gregg, and Ramirez (2017) found that levels of knowledge sharing within virtual groups affects trust. Fuller, Marett, and Twitchell (2012) found, not surprisingly, that deception within a virtual group hurts trust. The level of trust within virtual groups affects other group aspects. Peñarroja, Orengo, Zornoza, Sánchez, and Ripoll (2015) looked at how virtual group trust affects group feedback. The higher the level of group trust, the more effective group feedback is to improve information processing and learning within the group.

Strategies to build and maintain trust within a virtual group include regular and appropriate communication between members and between a group and its manager (Ford, Piccolo, \& Ford, 2017). Using video conferencing technology, chat, email, and web pages regularly can increase trust (Breuer et al., 2016). In addition, Breuer et al. (2016) suggests that the ability to document these types of communication may directly increase trust within a virtual group. Student cohorts using communication technology 
found the flexibility it offers a great benefit as it allows for instant communication between members at any time to collaborate or share struggles (Wolfe, Nelson, \& Seamster, 2018).

Differences between virtual group leadership and co-located group leadership styles may become less distinct. Participants in a study by Al-Ani, Horspool, and Bligh (2011) reported similar traits as being important for leaders of both co-located and virtual groups, with task and socio-emotional processes deemed most important. However, leader skill and ability with technology does matter. Given the fact that leading virtual groups requires effective use of computer-mediated communication, managers must be proficient in this technology (Iorio \& Taylor, 2015). Managers can enhance virtual group member trust by ensuring procedures, processes, tools, and practices employed by group members are in alignment with their organization's (Bisbe \& Sivabalan, 2017).

Evaluating the effect of variables, such as communication and trust, on virtual group effectiveness has been widely researched. Maynard and Gilson (2014) show that shared mental models within virtual groups is essential in determining effectiveness. In addition, they linked types of communication technology used by groups to how well those shared mental models are developed.

Other research connects trust to effectiveness. Appropriate project coordination promotes trust and cohesion leading to increased effectiveness (Paul et al., 2016). Trust, information sharing, and communication were identified as factors in virtual group effectiveness by Bhat, Pande, and Ahuja (2017). A study by Breuer et al. (2016) shows a positive relationship between group trust and group effectiveness and that relationship is even stronger for virtual group than face-to-face groups. Ford et al., (2017, p. 33) also 
linked trust to virtual group effectiveness claiming, "for people to work effectively when the primary means of communication is computer-mediated, there must be a strong and enduring foundation of trust." Contradictory research found that, while group trust has a positive influence on virtual group collaboration, it does not significantly influence effectiveness (Alsharo et al., 2017).

Two studies warn against the dangers of group and individual overconfidence. Park, Kim, and Gully (2017) advise leaders to find a balance with virtual group efficacy. Low group confidence creates barriers to group effectiveness while overconfidence leads to complacency. Similarly, Daniel, Nienaber, and Schewe (2016) found that individual self-performance perception was usually higher than actual performance, which can lead to members believing they are contributing more than their counterparts, which in turn reduces group trust. They caution virtual group leaders to provide clear individual and group performance measurements regularly.

Performance. A frequent focus in group cohesion research is attempting to determine how group cohesion affects performance. A strong correlation exists between group efficacy and group cohesion. Group performance is high when group cohesion is high and vice versa (Park et al., 2017). Gully, Devine, and Whitney (2012) suggest that the nature of a task determines the level of the cohesion-performance relationship. High task interdependence makes the cohesion-performance relationship stronger than when task interdependence is low.

Personality and emotions affect performance in virtual teams. Virtual group members form impressions of other group members even with the absence of face-to-face cues like facial expressions and body language. Using factors such as communication 
content and writing style, virtual group members judge the emotional authenticity of one another and compare those decisions with their own preconceived ideas of expected member behaviors. Member impressions regarding one another affects trust which then impacts group behaviors ultimately affecting group performance (Connelly \& Turel, 2016). In a study using the Big Five Personality Factors, Cogliser, Garner, Gavin, and Broberg (2012) linked virtual group member personality type with group performance. Not surprisingly, groups with highly conscientious and agreeable members had increased levels of performance.

\section{Summary}

The variable of cohesion has been deemed to be the most important aspect of group dynamics (Carron \& Brawley, 2012). It is basic to group functioning (McLeod \& von Treuer, 2013). The literature on group cohesion is extensive. Nevertheless, there is no single standard or definition of cohesion (von Treuer et al., 2013).

The multidimensional treatment of cohesion has often included task and social cohesion. Individual group members and groups as a whole experience both types (von Treuer et al., 2013). Task cohesion is based on a group's shared commitment to completing goals (Mason \& Griffin, 2003). Interpersonal attraction and individual interaction are referred to as social cohesion (McLeod \& von Treuer, 2013). Early in group formation, measurements of task cohesion are likely more valid than those for social cohesion (Salas et al., 2015). Group cohesion develops over time and is affected by length of time a group has been or will be together (Kozlowski, 2015).

A major research topic is how group cohesion affects group performance. Group cohesion is a chief influence on performance (Shiue et al., 2010). Carless and De Paola 
(2000) determined that task cohesion is more strongly related to group performance than social cohesion. When cohesion is measured during the group's existence matters. Cohesion and performance measures early in group formation may not be as strong as when measured during the latter stages of group existence (Salas et al., 2015).

Communication is key for group members participating using virtual communication technology (Breuer et al., 2016). Virtual group communication requires members to set norms early in group formation. The norms must include communication patterns such as type, timing, and content (Paul et al., 2016). Frequent and appropriate communication is essential to building group trust (Schulze \& Krumm, 2016) which is a component of group cohesion (Breuer et al., 2016). Virtual, partially distributed group must follow the same guidelines for communication (Susskind \& Odom-Reed, 2019). Another concern for virtual and virtual, partially distributed groups is the lack of communication cues such as facial expressions and body language. Interpersonal relationships are more difficult to form with the constraint of collaborating using virtual communication technology as members may be unable to hear tone of voice or see facial expressions of fellow group members (Schmidtke \& Cummings, 2017). 


\section{SECTION FOUR:}

\section{CONTRIBUTION TO PRACTICE}

To be presented to the site institution's statewide cooperative doctoral program

committee. The presentation will take place at a time most convenient for all committee members with the understanding that the current state of the COVID-19 pandemic may delay or alter presentation delivery. 


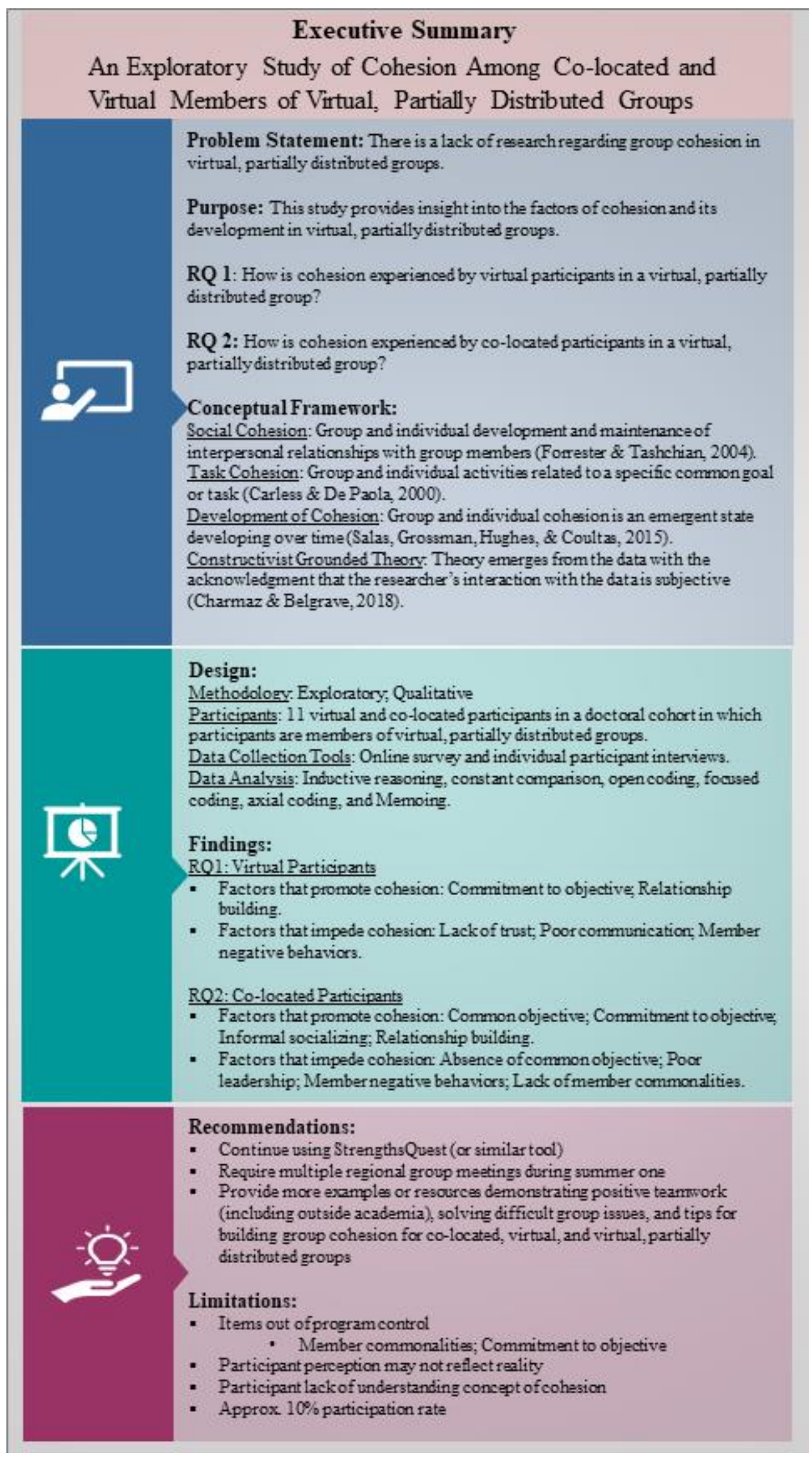




\section{Presentation Slides}

\section{An exploratory study of cohesion among co-located and virtual members of virtual, partially distributed groups}

A qualitative study by Sandy Harding

Statement of the problem

- Working and learning remotely using virtual communication technology is increasing.

- One form of a virtual group is a hybrid of completely co-located and completely virtual: Virtual, partially distributed.

- Most research focuses on either traditional co-located groups or completely virtual groups.

- Few studies focus or include virtual, partially distributed groups. 


\section{Purpose of the study}

- Provide insight into the factors of cohesion and its development in virtual, partially distributed groups.

- Research on group cohesion has shown its importance in individual and group success and member satisfaction (Marlow, Lacerenza, \& Salas, 2017).

- This study helps fill the gap in research on both virtual, partially distributed groups and how the co-located and virtual members experience cohesion.

\section{Research questions}

- $R Q$ 1: How is cohesion experienced by virtual participants in a virtual, partially distributed group?

- RQ 2: How is cohesion experienced by co-located participants in a virtual, partially distributed group? 


\section{Conceptual framework}

\section{Social cohesion}

- Term used to describe group activities related to or influenced by interpersonal relationships (Forrester \& Tashchian, 2004).

- Social cohesion may be experienced differently by co-located group members as compared to virtual group participants.

- The construct of cohesion lacks a universal definition.

- For this research cohesion is defined as the individual member's feeling and attitudes toward other members and the group, their sense of belonging, and commitment to the group.

\section{Conceptual framework}

Task cohesion

- Term used to describe group and individual activities related to or influenced by a common goal or task (Carless \& De Paola, 2000).

- Task cohesion may occur more quickly than social cohesion (Carless \& De Paola, 2000).

- Task cohesion is usually the focus of research over social cohesion regarding group achievement (Eys \& Carron, 2001). 


\section{Conceptual framework}

Development of cohesion

- Group and individual cohesion is an emergent state developing over time (Salas, Grossman, Hughes, \& Coultas, 2015).

- Actions or processes of group members contribute to the development of levels of cohesion (Marks, Mathieu, \& Zaccaro, 2001).

- Definitions of cohesion vary depending upon its state of development at the time of the study (Salas et al., 2015).

- Chiocchio and Essiembre (2009) suggest groups must be organized for a minimum of four weeks to develop cohesion before it is developed sufficiently to measure.

\section{Conceptual framework}

Constructivist grounded theory

- Grounded theory seeks to explain social processes rather than describing them to discover a theory (Creswell, 2013).

- With constructivist grounded theory, the theory emerges from the data with the acknowledgment that the researcher's interactions with the data is subjective (Charmaz \& Belgrave, 2018) 


\section{Design of the study}

- Methodology

- Exploratory

- Qualitative

- Participants

- 11 virtual and co-located participants in a doctoral cohort in which participants are members of virtual, partially distributed groups.

\section{Design of the study}

- Data collection tools

- Online survey using Qualtrics

- Demographic data and open-ended question about cohesion

- Semi-structured interviews using Zoom

- Participants described experiences that promoted and impeded cohesion in settings inside and outside of the statewide doctoral program

- Participants shared thoughts about how the program could adjust to better facilitate cohesion 


\section{Design of the study}

- Data analysis

- Open coding

- Focused coding

- Axial coding

- Constant comparison

- Inductive reasoning

\section{Findings}

- RQ 1:How is cohesion experienced by virtual participants in a virtual, partially distributed group?

- Factors that promote cohesion

- Commitment to objective (task)

- Relationship building(social)
- Factors the impede cohesion

- Lack of trust

- Poor communication

- Member negative behaviors 


\section{Findings}

- RQ 2:How is cohesion experienced by co-located participants in a virtual, partially distributed group?

- Factors that promote cohesion

- Commitment to objective (task)

- Common objective (task)

- Informal socializing (social)

- Relationship building (social)
- Factors that impede cohesion

- Absence of common objective

- Poor leadership

- Member negative behaviors

- Lack of member commonalities

\section{Illustrative Quotes}

Common Objective

- "We all have a common goal and we know where we are going. So, I would say clear expectations."

Commitment to Objective:

- "We have a lot of people that take initiative in getting things done. That has kind of set a standard of what is expected, and everyone wants to do their part. That is a positive because, even though we are busy, everyone wants to do their share."

Relationship Building:

- "Relationship building is huge so people will trust because you have to have trust so that people will actually open up and tell their thoughts and what their feelings are about things."

Supportive Leadership

- "Our professor has done a great job of giving us teamwork activities so we can learn about each other and our work styles." 


\section{Recommendations for practice}

- Continue using StrengthsQuest (or similar tool)

- Participants found this helpful to understand other group members

- Require multiple regional group meetings during summer one

- Participants felt more comfortable beginning the first fall semester when they met with their regional cohort multiple times during summer one

- Provide more examples or resources

- Demonstrating positive teamwork (including outside academia)

- Solving difficult group issues

- Tips for building group cohesion for co-located, virtual, and virtual, partially distributed groups 
SECTION FIVE:

CONTRIBUTION TO SCHOLARSHIP 
AN EXPLORATORY STUDY OF COHESION AMONG DOCTORAL STUDENTS IN VIRTUAL, PARTIALLY DISTRIBUTED GROUPS

To be submitted to the International Journal of Doctoral Studies 
Abstract

Aim/Purpose

Background

Methodology

Contribution

Findings

Recommendations for Practitioners
The purpose of this study was to explore how co-located and virtual participants in a virtual, partially distributed doctoral cohort experience cohesion.

Many groups work virtually from disparate locations. Group cohesion is essential to group success. Group dynamics has been well studied for co-located groups but groups whose members collaborate using virtual communication technology has not.

A qualitative exploratory research design examined how colocated and virtual group participants experienced cohesion. Participants were part of a doctoral cohort. Data was gathered using a demographic survey and individual interviews. Data analysis was accomplished through open, focused, and axial coding.

Recent developments surrounding COVID-19 have brought to the forefront the need for data regarding working, learning, and collaborating remotely. Although there is an abundance of research on cohesion in traditional co-located groups, studies of cohesion in groups whose members all work remotely or those with a mixture of co-located and virtual participating members is less common. This study provides insight into the development and preservation of cohesion among co-located and virtual members of a virtual, partially distributed doctoral cohort.

Virtual and co-located participants expressed a sense of cohesion in both task and social areas. Task cohesive factors include having a shared goal, a commitment to goal achievement and overcoming challenges. Social cohesive factors include identification with group members, open communication, sharing personal life information and informal individual socializing which were all components of relationship building. Virtual participants were more focused on factors that affected individual task (commitment to goal) and social cohesion (identification with other members) than on those that impact group cohesion such as group social activities.

For those responsible for group formation, consider individual strengths and weaknesses, talents, skills, and abilities prior to 
Recommendations for Researchers

Impact on Society

Future Research

Keywords determining group membership. Encourage some face-to-face collaboration, when possible. Leaders must provide clear, welldefined group objectives and foster group cohesion by facilitating team building opportunities. For group members, recognize task cohesion may develop more quickly than social cohesion. Group members can help facilitate cohesion by completing tasks, scheduling time for socializing, sharing personal self with the group, and behaving respectfully.

This research found that group and individual cohesion is promoted by factors such as sharing a common goal, supportive leadership, member commonalities, and appropriate communication. Researchers of group and individual cohesion can use the results to further understand the development of cohesion within virtual, partially distributed groups.

This study explores group cohesion in virtual and virtual, partially distributed groups. Recent public health developments with COVID-19 have forced many to become remote workers and learners. Practitioners can use the results to inform decisions regarding group formation and understand the importance of group and individual cohesion on success and satisfaction. Recognizing the essential factors that promote cohesion will help leaders facilitate its development, if not already present, and sustain it throughout the duration of the groups existence. Virtual learning is already a staple in many higher learning institutions and has increased due to the pandemic. Coordinators and leaders of doctoral programs can use this research to more deeply understand the most important factors of cohesion and the key distinctions between task and social cohesion for those enrolled in doctoral programs.

Future research in this area could expand on these findings by conducting longitudinal studies of doctoral cohorts. COVID-19 has forced many workers and learners to suddenly alter daily routines. Researchers should seize opportunities to study the effects of this change in routine on established group and individual cohesion and the development of cohesion among newly formed groups working and learning remotely. The findings suggest that task cohesion develops more quickly than social cohesion in a doctoral cohort. Specifically, more research is needed on how social cohesion develops over time and the sequence of this development in doctoral cohorts.

Cohesion, group cohesion, co-located groups, virtual, partially distributed groups, doctoral cohort 


\section{Introduction}

Technology in the past few decades has introduced a new facet to group or groupwork that is now commonplace, but under-studied. Today, many groups work disparately, in far-flung locations, yet they are still able to work together toward a common goal collaborating on company or organizational projects (Großer\& Baumöl, 2017). There are three types of distributed collaborative groups. In virtual groups all members participate via virtual communication technology rather than traditional face-toface (Haines, 2014). Co-located groups with two or more groups meeting in geographically disparate locations using virtual communication technology to collaborate between groups are another type (Daim et al., 2012). The type of group this study researched was a virtual, partially distributed group. Members in this type of group are both co-located and geographically dispersed (Eubanks et al., 2016).

One area utilizing virtual groups is higher education. Online courses have become increasingly popular with both educational institutions and students (Grinnell et al., 2012). This also allows students to pursue educational opportunities beyond a restricted commuting circumference around a brick and mortar institutional location. Those courses in which students are participating using virtual communication technology present new challenges in ensuring student achievement. Group cohesion has been shown to affect performance and success (Salas et al., 2015). The goal of this research was to explore the aspects of group cohesion of both co-located students and those participating using virtual communication technology. 


\section{Purpose}

This study endeavors to add to previous research on group cohesion focusing on a single, specific doctoral program with five cohorts, consisting of virtual, partially distributed members. The purpose was to discover how the cohort members experience group cohesion during the coursework portion of the program. Berry (2017) found that students who are part of a cohort experience a sense of cohesion because they have the same goal, begin coursework simultaneously, and progress through their program together. The study applied the methods and measures use by von Treuer et al. (2013). von Treuer and colleagues sought to create an appropriate measure of group cohesion. They asked about experiences of group members and applied content analysis to examine the data. This study used similar research questions and applied content analysis in a comparable manner.

What is missing in the research are empirical studies of the components identifying group cohesion and assessing, with similar methodologies, to what extent those components are similar or different for virtual, partially distributed groups. Because group cohesion is developmental, it may progress differently for co-located group members than for those members participating using virtual communication technology. Understanding and to better facilitate cohesion within this virtual, partially distributed cohort could be helpful for their success.

This study adds to current research on group cohesion concentrating on a virtual, partially distributed doctoral cohort to explore the following research questions.

RQ 1: How is cohesion experienced by virtual participants in a virtual, partially distributed group? 
RQ 2: How is cohesion experienced by co-located participants in a virtual, partially distributed group?

\section{Literature Review}

In exploring how virtual and co-located group members experience cohesion it is crucial to delve into the various ways group cohesion has been studied and addressed. Although this study will focus on task and social cohesion and how it may change over the duration of a group's existence, surveying the construct and various definitions of cohesion presented in the literature provides a solid foundation for the conceptual framework of this research.

\section{Co-located Group Cohesion}

Co-located group cohesion has been a well-researched concept in the last 50 years (Greer, 2012). In studies researching small groups, the most significant factor has been cohesion (Carron \& Brawley, 2000). A major problem with the concept of group cohesion is there has been no agreed upon comprehensive definition. Literature reviews reveal various descriptions and definitions of cohesion (McLeod \& von Treuer, 2013).

Definitions of group cohesion have evolved, and many group cohesion studies reference early definitions. Festinger (1950) defined cohesion as the "resultant of all the forces acting on members to remain in the group" (p. 274) Gross and Martin (1952) simplified a definition of cohesion as "the resistance of the group to disruptive forces" (p.553). Later definitions narrowed, becoming more specific and include variables. For example, group cohesion is determined by members acceptance of shared goals and the level of unity among members to achieve the goals (Shiue et al., 2010). 


\section{Virtual Group Cohesion}

Some researchers have looked at the components of virtual group cohesion (Breuer et al., 2016) or how virtual group cohesion impacts performance (Paul et al., 2016). As with co-located group cohesion, communication and trust are important factors influencing levels of cohesion in virtual groups (Thiss, 2017). Studies involving groups using virtual communication technologies to complete projects or accomplish goals concentrate on communication and communication technologies, trust, performance, and cohesion with most attempting to show connections between two or more of these aspects.

Communication is a key component of group processes because it is through communication that groups collaborate, solve issues, make decisions, and share knowledge. The quality, content, and frequency of communication are frequently the focus of research. Quality and content of communication is far more important than frequency (Marlow et al., 2017). Several issues arise when communication is lacking in virtual groups. Group members are not in sync regarding work flow, goals, or current status of a project and may be duplicating or neglecting tasks. Lack of communication can also lead to misunderstandings and mistrust within the group (Reed \& Knight, 2009). The types and amount of communication for virtual groups are dependent upon many factors, one of which is the stage of group and project development. Haines (2014) found that the amount of communication, and details contained therein, were higher at the initial stages of group and project development. After determining group structure, goals, task assignments, and roles, groups tended to simply complete individual tasks, decreasing the amount of communication. 
Virtual communication technology includes e-mail, instant messaging applications or software, and video and audio conferencing (Schaefer \& Erskine, 2012). Other methods of sharing information or documents include document storing and sharing platforms such as Google Docs and Microsoft's SharePoint and OneDrive. These types of document sharing platforms allow for virtual communication since group members with access can edit documents and insert comments within the documents. Using communication technology allows for collaboration between group members to complete work. Building relationships through the use of communication technology can be more difficult. The complexity of communication involves much more than words. Non-verbal communication such as body language, facial expression, tone of voice, verbal inflection, gestures, and even clothing choices convey messages.

Trust in virtual groups is another area of study, most focusing on the levels of trust in virtual groups and strategies to build trust. Alsharo et al. (2017) found that levels of knowledge sharing within virtual groups affects trust. The level of trust within virtual groups affects other group aspects. Peñarroja et al. (2015) looked at how virtual group trust affects group feedback. The higher the level of group trust, the more effective group feedback is to improve information processing and learning within the group.

Strategies to build and maintain trust within a virtual group include regular and appropriate communication between members and between a group and its manager (Ford et al., 2017). Student cohorts using communication technology found the flexibility it offers a great benefit as it allows for instant communication between members at any time to collaborate or share struggles (Wolfe et al., 2018). 
Differences between virtual group leadership and co-located group leadership styles may become less distinct. Participants in a study by Al-Ani et al. (2011) reported similar traits as being important for leaders of both co-located and virtual groups, with task and socio-emotional processes deemed most important. However, leader skill and ability with technology does matter. Given the fact that leading virtual groups requires effective use of computer-mediated communication, managers must be proficient in this technology (Iorio \& Taylor, 2015). Managers can enhance virtual group member trust by ensuring procedures, processes, tools, and practices employed by group members are in alignment with their organization's (Bisbe \& Sivabalan, 2017).

\section{Virtual, Partially Distributed Group Cohesion}

Membership in virtual, partially distributed groups comprise both co-located and virtual participants. As in other group research, studies involving virtual, partially distributed groups center primarily on communication, trust, performance, leadership, and technology. Communication, trust, performance, and leadership are of great concern, regardless of the type of group, because each area plays a significant role in group dynamics (English, 2017). The technology aspect is especially important for these groups since the primary means of communication and collaboration occurs via virtual communication technology. Group cohesion is linked to group and individual performance and success (Susskind \& Odom-Reed, 2019). Levels of group cohesion are directly impacted by communication, trust, leadership, and technology (Haines, 2014; Paul et al., 2016; von Treuer et al., 2013)

Few studies on virtual, partially distributed groups have been published making it difficult to adequately address in a literature review. Research focuses on co-located 
groups or geographically dispersed groups with no members meeting face-to-face. Many of the studies regarding virtual teams previously covered in this section are somewhat applicable to virtual, partially distributed groups. The research on virtual groups and communication, trust, performance, leadership, and technology may apply to the virtual members of virtual, partially distributed groups. However, they are not specific to the hybrid nature of virtual, partially distributed groups and there are some studies that do apply specifically to those groups with a mixture of co-located and virtual communicating members.

A few studies of virtual, partially distributed groups or partially distributed groups examine group cohesion. Relating to the temporal nature of the development of group cohesion, a study by Susskind and Odom-Reed (2019) found that participants reported higher levels of team cohesion during the final phase of project completion. They also found that group member performance increased as member perceptions of cohesion grew.

Other studies offer findings that suggest ways in which dispersed groups achieve cohesion. Group members who are willing to share personal life stories and information engender interpersonal feelings of familiarity thereby increasing cohesion (Chiu \& Staples, 2013). Groups can also enhance cohesion by developing a social identity around the project. Petter and Carter (2017) also found that the development of subgroups can lead to conflicts within the group. This may be a concern with virtual, partially distributed groups in that the co-located members may form such a subgroup leaving the virtual group members feeling left out. This would have a negative impact on group 
cohesion in general and the co-located and virtual members' perceptions of cohesion may vary greatly.

Eisenberg et al. (2019) found links between transformational leadership of geographically dispersed teams and team communication and performance. The higher the geographic dispersion of group members, the lower the leader's influence on communication and performance. As distance increases, communication decreases. The distance may interfere with the dispersed members seeing the leader as authentic. Lacking the social nuances, such as tone of voice, body language, and facial expressions, that are more apparent in face-to-face communication, even true transformational leaders may have to make extra efforts to convey their goals to dispersed group members.

\section{Task and Social Cohesion}

As definitions of group cohesion evolved, a common division of cohesion into two types, task and social, emerged (Carless \& De Paola, 2000; Eys \& Carron, 2001; Mason \& Griffin, 2003; Salas et al., 2015). Cohesion has been identified as an integral part of group dynamics (McLeod \& von Treuer, 2013), has been studied to determine its effect on group performance (Eys \& Carron, 2001) usually studying task cohesion over social cohesion when researching group achievement (Carless \& De Paola, 2000). Task cohesion is the level of group commitment to accomplishing a task or goal (Carless \& De Paola, 2000). Social cohesion refers to the bonds, such as friendship and compatibility, within a group based on social relationships (Mason \& Griffin, 2003). The early definitions with verbiage like "forces acting on members" (Festinger, 1950, p.274) and "resistance to disruptive forces" (Gross and Martin, 1952, p. 553) appear to fall into the current social cohesion category. 
As social and task cohesion are concepts directly related to the research questions, prior research on these is especially important. Research participants were grouped and given a specific predetermined project or task as part of fulfilling course requirements. Because they had the same goal of successful completion of the project, task cohesion was likely. However, how the groups decided to achieve the task or project had an impact on cohesion.

\section{Development of Cohesion}

Group members do not instantly form cohesive bonds with one another, rather groups grow in stages. Ito and Brotheridge (2008) researched four stages a group progresses through: forming, storming, norming, and performing. Group creation occurs during the forming stage. The storming stage refers to group conflict, sometimes as members express opinions, adjust to one another's communication and work style, and members assert power. The norming stage happens as compromises and agreements are reached. Performance is the final stage when group members are familiar with one another, have accepted and behave within the agreed upon norms, and are able to focus more completely on the accomplishment of group objectives (Bonebright, 2010). Future group cohesion is however dependent upon the groups handling of a previous stage of growth.

A concern with the construct of group cohesion is the linear nature of the development of group cohesion and cohesion as an emergent state (Gilson et al., 2015). While interaction occurs among members, cohesion is a possible outcome (Salas et al., 2015). Acknowledging group cohesion as an emergent state requires recognition that it is 
a process that may be erratic and dependent upon variables, such as, changes in group membership, tasks, assigned roles, or goals (Kozlowski et al., 2016).

Where a group is concerned, there must be a level of cohesion (Carron \& Brawley, 2012). Arguing that the definition of cohesion used in a study directly affects the research outcome, Carron and Brawley (2012) offer their own definition. Cohesion is "a dynamic process that is reflected in the tendency for a group to stick together and remain united in the pursuit of its instrumental objectives and/or for the satisfaction of member affective needs" (Carron \& Brawley, 2012, p. 731). One issue with Carron and Brawley's (2012) definition of cohesion is that is does not account for groups who have little choice in sticking together to achieve a goal. Participants in this study would have had to be willing to accept a failing grade or even drop from the program if they refused to stick together to complete their assigned project.

\section{Methods}

\section{Setting}

The setting for this research was a specific doctoral program with a cohort consisting of virtual, partially distributed members at various locations throughout a single state. Although historically this doctoral program has allowed a few students who had already completed considerable coursework to continue participation using virtual communication technology, the program began the 2019 cohort with several members using virtual communication technology from anywhere in the world as the primary means of collaboration and program completion. Most of the cohort members using virtual communication technology were located within the United States and all cohort members must participate in person during the two summer sessions. 
This program comprises five satellite universities within the state all participating as part of a cooperative educational doctorate program with a maximum capacity of approximately 18 students per satellite cohort, or up to 90 students total. The entire cohort meets during two summers, four weeks each, for intense course and group project completion. The remaining courses are held at the satellite campuses. Many cohort members attend classes at the satellite campus located nearest them geographically. Some of the cohort members attend classes using virtual communication technology. For example, a campus may have 18 members overall with 12 members physically present in the classroom and 6 members using virtual communication technology as the means of attendance. In addition, these 18 members may be divided into smaller groups to complete course projects during a semester. These smaller groups may utilize virtual communication technology in the process of collaboration to finish the group project. The groups are virtual, partially distributed teams since some members attend in a traditional fashion face-to-face and others attend virtually.

\section{Participants}

All 90 cohort members were invited to participate. An invitation to participate was sent by email to 8 instructors requesting they provide the information regarding the study and extend the invitation to participate to their students. The researcher, via virtual communication technology, also to spoke to students during a mid-semester session at one of the satellite campus locations. At that time, the researcher again extended the invitation for student participation, gave a brief overview of the study, and answered questions. Those willing to participate indicated so by emailing the researcher. Students who agreed to participation were emailed a survey link via Qualtrics. Twenty completed 
the survey with 11 indicating within the survey they were willing to complete the interview. Interviews were scheduled via email.

Interview participants indicated they regularly use virtual communication technology and were comfortable using it. Other survey results are displayed in Table 1. Table 1

Participant Demographic Summary

\begin{tabular}{|c|c|}
\hline Demographic Factor & $\begin{array}{l}\text { Percentage of total } \\
\text { participants }\end{array}$ \\
\hline \multicolumn{2}{|l|}{ Gender } \\
\hline Male & $36 \%$ \\
\hline Female & $64 \%$ \\
\hline \multicolumn{2}{|l|}{ Race/Ethnicity } \\
\hline Black or African American & $18 \%$ \\
\hline Native Hawaiian or Other Pacific Islander & $9 \%$ \\
\hline White & $73 \%$ \\
\hline \multicolumn{2}{|l|}{ Age } \\
\hline Under 30 & $9 \%$ \\
\hline $31-44$ & $82 \%$ \\
\hline $46-60$ & $9 \%$ \\
\hline \multicolumn{2}{|l|}{ Career Field } \\
\hline Elementary Education & $18 \%$ \\
\hline Secondary Education & $18 \%$ \\
\hline Higher Education & $55 \%$ \\
\hline Other & $9 \%$ \\
\hline \multicolumn{2}{|l|}{ Years in Profession } \\
\hline Less than 5 years & $9 \%$ \\
\hline $5-10$ years & $36 \%$ \\
\hline 11-20 years & $46 \%$ \\
\hline 21 or more years & $9 \%$ \\
\hline
\end{tabular}

Note. Only includes interview participant survey responses. 


\section{Data Collection}

Survey questions along with the consent form was sent to participants via email using Qualtrics to gather demographic information. The survey consisted of ten questions: three demographic questions, two regarding primary career field and years of experience in that field, two inquiring about their use of virtual communication technology, one question to briefly explore their emerging understanding of cohesion within their virtual, partially distributed cohort, and an item on whether they would agree to meet with the researcher for the interview portion of the study.

Interviews questions were based on von Treuer et al. (2013) and were altered and tailored to fit the co-located and virtual participants, and the research questions in this research. Interviews lasted approximately 20-30 minutes each and were conducted near the end of the Fall 2019 semester. A consent script was read by the researcher at the start of each interview (see Appendix D) at the end of which the participant was asked to verbally consent to continue with the interview. The interview questions (see Appendix E) asked about previous and current group cohesion experiences. Participants were asked to share a) experiences of group cohesion or lack of cohesion within their current doctoral cohort, b) experiences of group cohesion or lack of cohesion with a group outside of the doctoral cohort, c) thoughts about the essential factors affecting cohesion, and d) recommendations of way the doctoral program may be adjusted to better facilitate cohesion. The interviews were semi-structured. A semi-structured interview elicits specific information from respondents using a structured list of questions but allows for flexibility of the interviewer to use own discretion to respond to certain situations and responses during the interview (Merriam \& Tisdell, 2016). Some interviews were video 
and audio recorded while others only contained audio. This option allowed for accurate transcription of exact responses from participants (Merriam \& Tisdell, 2016).

\section{Data Analysis}

Levels of analysis for the survey and interviews were at the individual and group levels. Survey data of demographics and experience were analyzed using descriptive analysis. Frequency distributions were applied to describe participant demographic, primary career field, years of experience and use of virtual communication technology responses. The survey item regarding the participant's definition of cohesion was analyzed using open coding.

Interviews were transcribed by numbering each line and double-spacing between speakers. Interview data used open coding content analysis to categorize responses for both the co-located and virtual members. Examples of categories for individual responses might include a sense of belonging, trust, group pride and commitment to project completion.

Open coding is the preferred method of initial analysis for grounded theory research (Charmaz, 2017). Coding organizes data into categories (Creswell, 2014). Initial coding analyzed the interview data distributing the responses into task and social cohesion categories, then group and individual task and social cohesion. Because constructivist grounded theory is this study's theoretical lens, data progressed to focused coding of each of the categories. Focused coding analyzes the initial open coding using frequency distributions of those codes to determine the codes that reappear most often (Rieger, 2018). 
Constructivist grounded theory makes use of inductive-abductive logic. The researcher inductively analyzes the data to form a hypothesis then uses abductive reasoning to determine the most likely explanation (Rieger, 2018). This type of reasoning was most apt for this study because participant experiences are subjective. They cannot be proven or disproven; only interpreted using a best educated guess based on the inductive-abductive reasoning process.

To control for researcher bias, throughout data analysis, the researcher wrote memos to reflect thoughts on emerging themes, categories, and ideas (Giles et al., 2016). Memoing also assisted the researcher with maintaining checks on self-preconceived notions and biases regarding coding and categorization of participant responses. Researchers are cautioned to avoid applying predetermined ideas to the data and writing memos is an essential step to inhibit this possibility (Rieger, 2018).

\section{Findings}

Several themes surfaced with analysis of the research findings Participant interviews revealed little difference in the experience of cohesion between virtual and colocated participants, addressing the two research questions. How do virtual participants in a virtual, partially distributed group experience cohesion? How do co-located participants in a virtual, partially distributed group experience cohesion?

Focused coding revealed many components of group cohesion including trust, common goals, communication, and interpersonal relationships. These components were then sorted into group task, individual task, group social, and individual social cohesion groups per virtual and co-located responses. Each of these groups had one category per group that appeared with much greater frequency than the others. 
Participants also weighed in on factors that impede cohesion. Those results were also sorted into task and social cohesive components. Factors impeding cohesion fell into group task and individual social cohesion. There were no responses that could be sorted into individual task or group cohesion categories.

\section{Co-located Participant Experiences: Promoting Cohesion}

Group task cohesion. Overall categories for group task cohesion are a) common objective, b) group norms, c) overcoming challenges, d) supportive leadership, and e) objective outcome. By far, the most important factor in group task cohesion for colocated participants is sharing a common objective (see Figure 1). Time and again participants referred to the necessity for a group to have a clear, well-defined group purpose. Included in this was the need to have clear, well-defined expectations regarding the means the group was supposed to use to achieve the goal and how the group would know they had reached the goal.

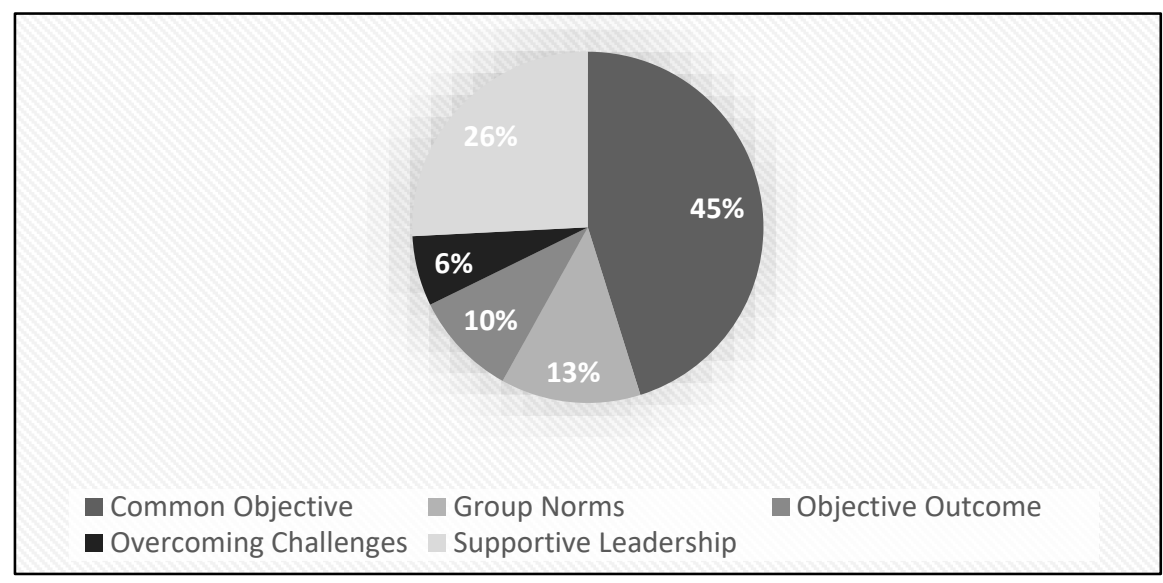

Figure 1. Categories of group task cohesion percentages for co-located participants.

Supportive leadership is linked to sharing a common objective because many time the leader is responsible for providing the group with a group purpose and laying out expectations. Leaders were also viewed as supportive when they provided opportunities 
that fostered group cohesion. Finally, supportive leaders cared about group members and looked out for the groups best interest. Table 2 provides examples of participant responses for each of the group task categories.

Table 2

Illustrative Quotes for Group Task Cohesion: Co-located

\begin{tabular}{ll}
\hline \multicolumn{1}{c}{ Category } & \multicolumn{1}{c}{ Participant Response } \\
\hline Common Objective & $\begin{array}{l}\text { "Everyone to be on the same page for the sake of the } \\
\text { program. We all had the same goals" (Participant 10). }\end{array}$ \\
Group Norms & $\begin{array}{l}\text { "One of the first things we did was set group norms. Later } \\
\text { we had a slight disagreement over something in our paper } \\
\text { and we just went back to our ground rule that it would be } \\
\text { decided by consensus" (Participant 4). }\end{array}$ \\
Overcoming Challenges & $\begin{array}{l}\text { "In a particular situation where the group was working on } \\
\text { a fairly arduous task that had taken a lot of time and } \\
\text { energy, when it was complete, we felt a sense of agency" } \\
\text { (Participant 3). } \\
\text { "Our professor has done a great job of giving us } \\
\text { teamwork activities so we can learn about each other and } \\
\text { our work styles" (Participant 2) } \\
\text { "We got along really well, and we're done with our } \\
\text { project early" (Participant 4). }\end{array}$ \\
\hline
\end{tabular}

Individual task cohesion. Task cohesion was also measured at the individual level. Commitment to objective was the sole category emerging from the data. Commitment to objective stood out as the essential factor promoting individual task cohesion. The term flexibility was repeatedly used to describe member commitment to completing a task, project, or scheduling collaboration. Members were willing to make accommodations to achieve the best possible outcome for the group's goal. Included in 
the commitment to objective category was individual members taking and sharing responsibility for completing tasks necessary for the success of the group. Individual members were willing to help other members with tasks in an effort to attain the shared goal. These behaviors indicated each members' motivation to do their best. Participant 10 shared this:

We have a lot of people that take initiative in getting things done. That has kind of set a standard of what is expected, and everyone wants to do their part. That is a positive because, even though we are busy, everyone wants to do their share.

Group social cohesion. Social cohesion at the group level revealed two main categories: informal socializing and group atmosphere (see Table 3). For the co-located participants, informal socializing was considered the most important factor for group social cohesion. Cohesion was fostered by group social events such as meeting for dinner or hanging out together after a group meeting. One participant shared that the group would go outside and throw a Frisbee for 20-30 minutes. In some instances, the social gathering followed a group success and was a group celebration.

The category of group atmosphere is separated from socializing because responses involved those times when the group was formally meeting or collaborating. Participants viewed a positive group atmosphere as collegial and collaborative. New members were welcomed to a group and made to feel comfortable. Table 3 shows sample responses for these two categories. 
Table 3

Illustrative Quotes for Group Social Task Cohesion: Co-located

\begin{tabular}{ll}
\hline \multicolumn{1}{c}{ Category } & \multicolumn{1}{c}{ Participant Response } \\
\hline Informal Socializing & $\begin{array}{l}\text { "At least once a week we are going to someone's house or } \\
\text { going out to eat or having a potluck and we all look } \\
\text { forward to those times" (Participant 1). }\end{array}$ \\
Group Atmosphere & $\begin{array}{l}\text { "It's important to have collegiality. That goes along with } \\
\text { being a professional group and so let's work in } \\
\text { professional ways" (Participant 3). }\end{array}$ \\
\hline
\end{tabular}

Individual social cohesion. The overarching category of relationship building is made up of several factors that promote cohesion. These factors work together to promote individual social cohesion. They are listed in Table 4.

Table 4

Individual Social Cohesion Factors: Co-located

\begin{tabular}{ll}
\hline \multicolumn{1}{c}{ Factor } & \multicolumn{1}{c}{ Descriptions } \\
\hline Trust & Honesty, trust given and received \\
Sharing & Personal information \\
Camaraderie & Laughter, small group socializing \\
Commonalities & Shared background, circumstances, beliefs \\
Communication & Small talk, giving feedback, sharing thoughts \\
Prior Familiarity & Members know one another already \\
& Giving and receiving respect, respect member \\
Respect & knowledge and talents \\
\hline
\end{tabular}

The factors listed above help individuals develop social cohesion with other group members. However, they appear to have an order in which they must occur for 
relationships to form. For instance, trust is part of relationship building but it does not occur until after some of the other factors.

As may be expected, participant responses revealed that communication is essential and the first factor that must occur to initiate the building of relationships. Chatting about daily life such as the weather, traffic, or current news items were ways they began getting to know group members. Sharing personal information was key so members could find commonalities amongst the individuals. The discovered commonalities allowed for more detailed sharing and bonding opportunities for individuals. The element of respect shown by members was necessary for members to feel comfortable sharing, especially personal information. Sharing facilitated members' trust in one another and a sense of ease with their respective groups.

Several participants indicated they had prior familiarity with some group members. Some knew each other in a workplace capacity such as working in the same district or on the same campus. Others had collaborated previously on professional committees. These participants had already formed relationships with one another. Table 5 gives examples of participant responses. 
Table 5

Illustrative Quotes for Relationship Building

Component Participant Response

Trust

"Relationship building is huge so people will trust because you have to have trust so that people will actually open up and tell their thoughts and what their feelings are about things" (Participant 9).

Sharing

Camaraderie

Commonalities

Communication

Prior Familiarity

Respect
"I think informal relationships helps build formal relationships because you get to share a little bit about yourself and that helps me understand the person that's in front of me" (Participant 1).

"We just kind of accepted each other for who we are, and I could just be myself. We laughed and had a good time" (Participant 4).

"If you can have something you all have in common that you can latch onto, in our case we're all spread across the country, that helps us build cohesion" (Participant 7).

"We get along well because everyone has been upfront about their strengths and weaknesses and it's been some of the most open conversations that I have had in any work or educational group instances" (Participant 5).

"We are all members of the same department and because this is a different group we've had to learn and develop cohesion in a little different way which was aided by our previous relationships" (Participant 2).

"We have a group member who does not drink or want to be around drinking for religious reasons. Out of respect for her, when we went out to dinner none of us ordered alcoholic beverages. It was the right thing to do" (Participant 8).

\section{Co-located Experiences: Impeding Cohesion}

Group Task Cohesion. Research participants indicated there were two main factors impeding task cohesion for their groups. First, the absence of a shared group goal 
caused the group to founder during the early stages of group formation. Participants saw the formation of a group without a clear purpose or expectations as the foundation for the failure of group cohesion. One consequence was that members disagreed about the group goals. As members sought to define a goal, they were headed in different directions and sometimes working at cross-purposes.

Poor leadership was also cited as impeding group cohesion. Some group leaders appeared to have their own self-interests in mind during meetings. Leaders who headed committees and set the agendas for meetings that were in the leaders best interest and not necessarily in-line with the stated group goal set the tone for a lack of group cohesion. In addition, those leaders who set unrealistic expectations for members also impeded cohesion as members experienced negative undertones and feedback when placing family before group commitments.

Individual social cohesion. Member negative behaviors and a lack of commonalities are the two main categories impeding individual social cohesion. Many participants listed negative member behaviors rather than providing long narratives surrounding their thoughts. Competition, negative conflict as opposed to positive conflict, social negativity, talking behind people's backs, and underhanded activities to undermine other group members were all mentioned briefly by various participants. These kinds of destructive behaviors were seen as significant blocks to group cohesion.

\section{Virtual Participant Experiences: Promoting Cohesion}

Virtual participants experienced many of the same factors that promote cohesion as did the co-located respondents. One exception is group social cohesion. Very little was mentioned in the interviews regarding social cohesion on the group level. 
Group task cohesion. Virtual participants indicated overcoming challenges and having a common objective as the two most important categories for group task cohesion. Challenges included reflecting and debriefing after analyzing task results, identifying pros and cons of a possible plan of action, and synthesizing various group member input. An additional challenge virtual participants sometimes faced involved technology failures during group collaboration. Being able to troubleshoot technology issues and find work arounds to communicate and complete tasks was essential for virtual participants to be able to remain contributing members of their groups.

Virtual participants responded similarly to co-located participants regarding the importance of a group common objective. Participants felt that cohesive groups must have a shared purpose and the purpose must be clear and well defined. They added that clearly defined expectations were also a necessity. Group members need a path to success and that means explicit and distinct expectations. Without these they felt that members would be headed in different directions and disagreeing about processes thus inhibiting group cohesion.

Individual task cohesion. Virtual participants viewed the commitment to objective category as significant for individual task cohesion as their co-located counterparts. Having a common goal was seen as essential, but not enough on its own. The shared goal and mutual commitment together provide a sense of cohesion. Individuals being flexible about task assignments so that the most effective and efficient plan for task completion was cited as a key factor. Participants want to know that other group members are going to put substantial effort, or at least match their own effort, into successfully reaching the shared purpose. 
Reciprocal feedback was also deemed important for virtual participants. Feeling comfortable giving and receiving honest feedback from group members occurred after there was a sense of cohesion. They also felt it was important to the overall success of the ultimate group objective. Group members feeling at ease to give their honest opinions led to a better final product which was important for both group and individual success.

Individual social cohesion. Virtual participants did not cite trust or member behaviors as important for individual social cohesion as co-located participants did. Relationship building was the overwhelming factor promoting cohesion according to virtual participants. Communication, finding commonalities, and prior familiarity were the main components of relationship building. For virtual participants, communication happened through technologies such as video conferencing, email, and chat formats. They used these methods to get acquainted and find similarities with each other laying the foundations for interpersonal relationships. Virtual participants also felt more at ease when they had previous knowledge or experience with one or more members of their group.

\section{Virtual Participant Experiences: Impeding Cohesion}

Virtual participants had little to say regarding factors that may impede group cohesion. Two of the five said they could not think of any characteristics or features of the group that prohibited cohesion. The other three respondents cited various issues such as a lack of trust, poor communication, and negative behaviors by some group members. During interviews these issues were casually mentioned with participants seeming to reach for something that might fit with impeding group cohesion. In addition, they 
appeared to be of little consequence to group cohesion in the eyes of the virtual participants.

\section{Flexibility as a Subordinate Theme}

A term used frequently by all participants when describing cohesion was the word flexible. However, it was used in a variety of contexts that made it difficult to categorize and was insignificant when placed in categories based on the circumstantial meaning. A few references to flexibility involved scheduling meetings. A couple of participants mentioned flexibility when deciding on social gathering locations. Flexibility was also used to describe understanding other members workstyles and being tolerant of differences. Finally, the term was used as a synonym for adaptability and empathy based on the context of the participant's responses. The lack of flexibility in these areas was also mentioned as an aspect that impeded cohesion.

\section{Discussion}

Co-located and virtual participant responses indicated the most important group task cohesive factor was sharing a common objective. von Treuer et al. (2010) define cohesion "as the tendency for a group to stick together and pursue a common goal" (p. 42). Task cohesion developed quickly for these participants when there was a clear group purpose. Both groups found the lack of a common purpose an impeding factor for cohesion.

Both co-located and virtual participants found individual group members' dedication to completing tasks and attaining the overall goal as a factor promoting cohesion. However, this factor is directly tied to sharing a common goal. Without a clear and shared understanding of the group's objective, members were either lacking 
productive tasks to complete or working toward attaining an ambiguous objective that members saw as meaningless. Mullen and Cooper (1994) studied the relationship between group cohesiveness and performance calling it the cohesive-performance effect. Their findings support this research in that commitment to the task was essential for cohesiveness.

Both participant groups expressed a feeling of cohesion when groups had to overcome challenges and did so successfully. This could be considered a form of team building, although it is not intentional nor prescriptive. There are many companies and organizations that send employees or members to retreats or workshops to experience challenging tasks. They learn how to overcome those challenges successfully as a group with goals being to learn problem-solving skills and develop or strengthen group cohesion. Klein et al. (2009) research supports the effectiveness of intentional team building activities. Team building affects essential group aspects such as trust and cohesion (Shuffler et al., 2018). Thus, the unintended challenges groups may face and find ways to overcome, and the resulting effects of increased trust and group task cohesion may be similar to those used in purposeful team building interventions. Social cohesion involves group members developing positive interpersonal relationships with one another (von Treuer et al., 2018). Although virtual participants did not express feelings of group social cohesion as important, both participant groups viewed relationship building as an essential aspect of individual social cohesion. A feeling of belonging to the group and having a sense of inclusion are identified as important to the development of cohesion (vonTreuer et al., 2013). Several components were indicated as contributing to developing interpersonal relationships including prior 
familiarity with others, sharing personal information, sharing commonalities with other members, and open communication. The development of relationships went through stages in order for participants to have a sense of cohesion. It was necessary for members to share information about themselves, even those with some prior familiarity with other members, to begin discovering common ground.

Participant groups diverged in other areas. Co-located participants cited supportive leadership, the agreement on group norms, and group success as important for group task cohesion. Supportive leadership and workgroup efficacy boost member satisfaction with the group and increases feelings of cohesion (vonTreuer et al., 2013). Engaged and supportive leadership is to the development and maintenance of group cohesion (Noel, 2006). Virtual participants did not cite supportive leadership as a cohesive factor. Supportive leadership is more difficult to convey using virtual communication technology (Guinalíu \& Jordán, 2016). This may be especially true for leaders unaccustomed to leading virtual teams or virtual, partially distributed groups.

Another area of participant group divergence involves group social cohesion. Colocated participants expressed their feelings of cohesion grew as a result of group interactions that were unrelated to the groups goal or task completion. Members develop a sense of camaraderie as they engage in group social activities together and physical proximity facilitates this (vonTreuer et al., 2013). Group social activities are easier for co-located group members to engage in than virtual members and may have resulted in a lack of responses in this area from virtual participants.

Flexibility was considered an overall subordinate theme that did not fit properly in any single category. In addition, responses indicated that a lack of member flexibility was 
an impeding factor for cohesion. Participants use of the term varied in contextual

meaning as they used it to describe several types of situations fitting both task and social cohesion constructs.

\section{Impact on Society}

This study began just prior to the COVID-19 pandemic. Companies, educational organizations, governmental institutions, and the private sector have, out of necessity, made a switch to working remotely. Although it is predicted that the pandemic will end, using virtual communication technology to collaborate may be a new normal for many. The pandemic is testing the viability of working and learning remotely in mass numbers. The coming weeks and months will reveal the pros and cons for both, and it is likely that some companies and organizations will discover the benefits outweigh the drawbacks, in some cases, leading to an increase in future working and learning remotely (Lopez, March 27, 2020).

Even before the need to work and learn remotely, the increase in using virtual communication technology by groups to collaborate and produce an end product has been on the rise. About one-fourth of the U.S. workforce worked from home in 2019, either part or full-time (Larson et al., March 18, 2020). Leaders, managers, and the general public are looking for information about how they can help their remote employees and employee groups navigate working from home. As indicated in the literature review and throughout this study, group cohesion is critical to group success. This research directly addresses how co-located and virtual participants experience group cohesion. Although the two groups share many common concerns regarding cohesion, there were a few differences that were unique to virtual participants. 


\section{Recommendations for Practice}

Most of the recommendations for practitioners are for group or organizational leaders. Managers, supervisors, coordinators, and instructors who are responsible for providing group goals and possibly held accountable for group success must first furnish a group with the essential foundational components for the development of group cohesion. These include utilizing a group assessment that measures individual strengths or decision-making tendencies, regular meetings, appropriate resources, clear group goal(s), and team-building activities.

StrengthsQuest, StrengthsFinder, and Kolbe A are examples of individual assessments used to identify strengths and personal tendencies. The results of these or other similar tools can be useful when selecting group members. They allow for group diversity in individual strengths and allow group members to know their own and other members strengths and personal tendencies. This aids in task assignment, relationship building, and conflict resolution.

Regular group meetings, both in person or virtual, are key for socialization, knowledge sharing, and whole-group check-ins (Lilian, 2014; Mesmer-Magnus et al., 2011). When meeting using virtual communication technology, use the video capabilities regularly. These meeting provide time for team-building activities and this is as important for virtual groups as for co-located groups (Leading Virtual Teams, 2016). Team-building activities may be most important for virtual, partially distributed teams to inhibit the development of a social divide between the co-located and virtual group members (Willis, 2010). The development of cohesion is easier between co-located group members 
so leaders must be aware of and immediately address issues with virtual group members being sidelined or left out of group work or decisions (Paul et al., 2016).

Organizational and leader support includes giving groups appropriate resources and empowerment to use them (Levi, 2014). Provide groups with resources on developing and maintaining group cohesion, problem-solving for groups, and special challenges for virtual and virtual, partially distributed groups. Group members should be armed with knowledge of group problem-solving techniques. Understanding what cohesion is and being aware of how successful groups develop and maintain group cohesion will assist with the thoughtful, purposeful pursuit of group cohesion by members. Make groups aware of the special challenges that virtual and virtual, partially distributed groups sometimes face. Most of all, the resources and information should be given to groups at the earliest stage possible. Doing so can help head off small issues before they become large.

Leadership should provide clear, well-defined objectives for groups with specific role descriptions and delegations (Haines, 2014). Groups without a distinct understanding of the shared goal falter during the forming phase. As members begin trying to figure out and agree on the group's purpose, the group fractures into factions with each pursuing a different objective. Not only does this waste time and energy, but it is an impediment to group cohesion and the group remains in the storming phase, never reaching norming or performing.

Finally, leaders can foster group cohesion by creating and facilitating opportunities for team building (Klein et al. 2009). During group formation is when these types of activities are most important because groups are establishing interpersonal 
relationships (Bonebright, 2010). This is especially true when members are unknown to one another and when some or all group members participate using virtual communication technology. Team building activities allow for members to get to know each other, explore boundaries, learn individual member strengths, and lay the foundation for group cohesion. Later, when the group is working towards the goal, they have a basic understanding of other members and have begun the process of building relationships.

Group members also play a role in facilitating cohesion. Individuals can focus on completing assigned tasks in a timely manner, communicate openly including sharing personal self with other group members, and behaving with integrity. Groups should intentionally schedule time for socializing that does not involve group work.

\section{Future Research}

COVID-19 has compelled companies and educational institutions to modify methods of working and learning. Future research opportunities abound in this new reality. Prior to the pandemic, those who worked or learned in groups while physically present in the same location may have well developed cohesive relationships. Researchers can study how collaborating with their groups using virtual communication technology has affected feelings of cohesion. Do group members use the video option when meeting with their groups or simply rely on audio only? What impact has that had on media richness and group member's sense of cohesion? What methods are individuals and groups discovering to continue working toward their shared goals under pandemic conditions? How have current doctoral cohorts been affected by the current restrictions and changes on university campuses? 
Future research in the area of co-located and virtual group members' experiences of cohesion could expand on the findings of this study by conducting longitudinal research on a single cohort. It is possible, and even likely, that feelings of cohesion vary over time since the development of group cohesion is temporal. Studying participants over a longer period of time would provide a deeper understanding of group cohesion and improve validity of the findings.

Another possible area for future research would be finding respondents who are all part of a cohort one group comprised of only co-located members while the other is made up of only virtual members. This would allow for direct comparison of the two groups members experiences with cohesion. Ideally, another group within the cohort would contain both co-located and virtual participants making designating that group as virtual, partially distributed. Each group within the cohort would have the same group tasks to complete within the same timeline.

\section{Conclusion}

Co-located participants experienced cohesion in both task and social areas. They found sharing an objective an important factor in group task cohesion. On the individual level, demonstrating firm commitment to the group objective was viewed as a key factor in individual task cohesion. This commitment from members allowed individuals to have the flexibility to work around situations or circumstances and still be able to complete tasks in a timely manner.

Regarding social cohesion, co-located participants found informal socializing by the group an essential element in group cohesion. Co-located groups began bonding though group social events and continued to cement the groups cohesion throughout the 
groups duration. On the individual level, various aspects of relationship building were key for member feelings of cohesion.

Issues impeding cohesion for co-located groups were a lack of a common goal, poor leadership which was sometimes blamed for the lack of a common goal, and poor member behaviors. Overall, the factors they felt prohibitive to cohesion were the opposite or lack of those that promote cohesion.

Virtual participants had little input for group task or social cohesion. Their focus was on the individual aspects task and social cohesion. Virtual participants were most influenced by a member's commitment to the objective for individual task cohesion. Similar to the co-located group, virtual participants were affected by the flexibility allowed so members were able to navigate special circumstances in order to complete a task. Their experience regarding social cohesion was on the individual level and revolved around developing and maintaining interpersonal relationships. Very little insight was gained from virtual participants regarding impediments to cohesion. They too viewed the lack of the elements that promote cohesion as reasons for groups and individuals not experiencing cohesion. 


\section{References}

Al-Ani, B., Horspool, A., \& Bligh, M. C. (2011). Collaborating with 'virtual strangers': Towards developing a framework for leadership in distributed teams. Leadership, 7(3), 219-249. doi:10.1177/1742715011407382

Alsharo, M., Gregg, D., \& Ramirez, R. (2017). Virtual team effectiveness: The role of knowledge sharing and trust. Information \& Management, 54(2017), 479-490. doi:10.1016/j.im.2016.10.005

Berry, S. (2017). Student support networks in online doctoral programs: Exploring nested communities. International Journal of Doctoral Studies, 12, 33-48. Retrieved from http://www.informingscience.org/Publications/3676

Bisbe, J., \& Sivabalan, P. (2017). Management control and trust in virtual settings: A case study of a virtual new product development team. Management Accounting Research, 37(2017), 12-29. doi:10.1016/j.mar.2017.02.001

Bonebright, D. A. (2010). 40 years of storming: A historical review of Tuckerman's model of small group development. Human Resource Development International, 13(1), 111-120. doi:10.1080/13678861003589099

Breuer, C., Hüffmeier, J., \& Hertel, G. (2016). Does trust matter more in virtual groups? A meta-analysis of trust and group effectiveness considering virtuality and documentation as moderators. Journal of Applied Psychology, 101(8), 11511177. doi:10.1037/ap10000113

Carless, S. A., \& De Paola, C. (2000). The measurement of cohesion in work groups. Small Group Research, 31(1), 71-88. 
Carron, A. V, \& Brawley, L. R. (2012). Cohesion: Conceptual and measurement issues. Small Group Research, 43(6), 89-106. doi:10.1177/1046496412468072

Charmaz, K. (2017). Special invited paper: Continuities, contradictions, and critical inquiry in grounded theory. International Journal of Qualitative Methods, 16, 1-8. doi:10.1177/1609406917719350

Chiu, Y., \& Staples, D. S. (2013). Reducing faultlines in geographically dispersed teams: Self-disclosure and task elaboration. Small Group Research, 44(5), 498-531. doi:10.1177/1046196413489735

Creswell, J. W. (2014). Research design: Qualitative, quantitative, and mixed methods approaches (4th ed.). Thousand Oaks, CA: Sage.

Daim, T. U., Ha, A., Reutiman, S., Hughes, B., Pathak, U., Bynum, W., \& Bhatla, A. (2012). Exploring the communication breakdown in global virtual teams. International Journal of Project Management, 30, 199-212. doi:10.1016/j.ijproman.2011.06.004

Eisenberg, J., Post, C., \& DiTomaso, N. (2019). Team dispersion and performance: The role of team communication and transformational leadership. Small Group Research, 1-33. doi:10.1177/1046496419827376

English, M. (2017). Group dynamics. Salem Press Encyclopedia. Toledo, OH: Great Neck Publishing.

Eubanks, D. L., Palanski, M., Olabisi, J., Joinson, A., \& Dove, J. (2016). Team dynamics in virtual, partially distributed groups: Optimal role fulfillment. Computers in Human Behavior, 61, 556-568. doi:10.1016/j.chb.2016.03.035 
Eys, M. A., \& Carron, A. V. (2001). Role ambiguity, task cohesion, and task selfefficacy. Small Group Research, 32(3), 356-373.

Festinger, L. (1950). Informal social communication. Psychological Review, 57, 271282. doi: $10.1037 / \mathrm{h} 0056932$

Ford, R. C., Piccolo, R. F., \& Ford, L. R. (2017). Strategies for building effective virtual teams: Trust is key. Business Horizons, 60(1), 26-34. doi:10.1016/j.bushor.2016.08.009

Giles, T. M., de Lacey, S., \& Muir-Cochrane, E. (2016). Coding, constant comparisons, and core categories: A worked examples for novice constructivist grounded theorists. Advances in Nursing Science, 39(1), E29-E44. doi:

10.1097/ANS.0000000000000109

Gilson, L. L., Maynard, M. T., Young, N. C. J., Vartiainen, M., \& Hakonen, M. (2014). Virtual teams research: 10 years, 10 themes, and 10 opportunities. Journal of Management, 41,(5), 1313-1337. doi:10.1177/0149206314559946

Greer, L. L. (2012). Group cohesion: Then and now. Small Group Research, 43(6), 655661. doi:10.1177/1046496412461532

Grinnell, L., Sauers, A., Appunn, F., \& Mack, L. (2012). Virtual teams in higher education: The light and dark side. Journal of College Teaching \& Learning, 9(1), 65-79. doi:10.19030/tlc.v9i1.6716

Gross, N. \& Martin, W.E. (1952). On group cohesiveness. American Journal of Sociology, 57, 546-554.

Großer, B., \& Baumöl, U. (2017). Why virtual groups work - State of the art. Procedia Computer Science, 121, 297-305. doi:10.1016/j.procs.2017.11.041 
Guinalíu, M., \& Jordán, P. (2016). Building trust in the leader of virtual work teams. Spanish Journal of Marketing - ESIC, 20, 58-70. doi:10.1016/j.reimke.2016.01.003

Haines, R. (2014). Group development in virtual groups: An experimental reexamination. Computers in Human Behavior, 39, 213-222. doi:10.1016/j.chb.2014.07.019

Harvard Business Review Press (2016). Leading virtual teams (HBR 20-minute manager series). Boston, MA: Harvard Business Review Press.

Iorio, J., \& Taylor, J. E. (2015). Precursors to engaged leaders in virtual project teams. International Journal of Project Management, 33(2), 395-405. doi:10.1016/j.ijproman.2014.06.007

Ito, J. K., \& Brotheridge, C. M. (2008). Do teams grow up one stage at a time: Exploring the complexity of group development models. Team Performance Management, 14(5-6), 214-232. doi:10.1108/13527590810898491

Klein, C., DiazGranados, D., Salas, E., Le, H., Burke, C. S., Lyons, R., \& Goodwin, G. F. (2009). Does team building work? Small Group Research, 40(2), 181-222. doi:10.1177/1046496408328821

Kozlowski, S. W. J., Chao, G. T., Grand, J. A., Braun, M. T., Kuljanin, G. (2016). Capturing the multilevel dynamics of emergence: Computational modeling, simulation, and virtual experimentation. Organizational Psychology Review, 6(1), 3-33. doi:10.1177/2041386614547955

Larson, B. Z., Vroman, S. R., \& Makarius, E. E. (March 18, 2020). A guide to managing your (newly) remote workers. Harvard Business Review. Retrieved from https://hbr.org/2020/03/a-guide-to-managing-your-newly-remote-workers 
Levi, D. (2014). Group dynamics for groups (4th ed.). Thousand Oaks, CA: Sage.

Lilian, S. C. (2014). Virtual teams: Opportunities and challenges for e-leaders. Procedia Social and Behavioral Sciences, 110, 1251-1261. doi:10.1016/j.sbspro.2013.12.972

Lopez, M. (March 27, 2020). Stay-at-home orders could serve as an important test for the future of remote working. The Denver Channel.com. Retrieved from: https://www.thedenverchannel.com/news/360/stay-at-home-orders-could-serveas-an-important-test-for-the-future-of-remote-working

Marlow, S. L., Lacerenza, C. N., Paoletti, J., Burke, C. S., \& Salas, E. (2017). Does team communication represent a one-size-fits-all approach: A meta-analysis of team communication and performance. Organizational Behavior and Human Decision Processes, 144, 145-170. doi:10.1016/j.obhdp.2017.08.001

Mason, C. M., \& Griffin, M. A. (2003). Identifying group task satisfaction at work. Small Group Research, 34(4), 413-442. doi:10.1177/1046496403252153

McLeod, J., \& von Treuer, K. (2013). Towards a cohesive theory of cohesion. International Journal of Business and Social Research, 3(12), 1-11. doi:10.18533/ijbsr.v3i12.338

Merriam, S. B., \& Tisdell, E. J. (2016). Qualitative research: A guide to design and implementation. San Francisco, CA: Jossey-Bass.

Mesmer-Magnus, J. R, DeChurch, L. A., Jimenez-Rodriguez, M., Wildman, J., \& Shuffler, M. (2011). A meta-analytic investigation of virtuality and information sharing in teams. Organizational Behavior and Human Decision Processes, 115(2), 214-225. doi:10.1015/j.obhdp.2011.03.002 
Mullen, B., \& Cooper, C. (1994). The relations between group cohesiveness and performance: An integration. Psychological Bulletin, 115, 210-277. doi:10.1037/0033-2909.115.2.210

Noel, D. R. (2006). Cohesive strategies for group leadership: The relationship of cohesion to stages of group development (Doctoral dissertation). Retrieved from ProQuest. (9780542793271)

Paul, R., Drake, J. R., \& Liang, H. (2016). Global virtual group performance: The effect of coordination effectiveness, trust, and group cohesion. IEEE Transactions on Professional Communication, 59(3), 186-202. doi:10.1109/TPC.2016.2583319

Peñarroja, V., Orengo, V., Zornoza, A., Sánchez, J., \& Ripoll, P. (2015). How team feedback and team trust influence information processing and learning in virtual teams: A moderated mediation model. Computers in Human Behavior, 48, 9-16. doi:10.1016/j.chb.2015.01.034

Petter, S., \& Carter, M. (2017). In a league of their own: Exploring the impacts of shared work history for distributed online project teams. Project Management Journal, 48(1), 65-80. doi:10.1177/875697281704800105

Reed, A. H., \& Knight, L, V. (2009). Effect of a virtual project team environment on communication-related project risk. International Journal of Project Management,28(2010), 422-427. doi:10.1016/j.ijproman.2009.08.002

Rieger, K. L. (2018). Discriminating among grounded theory approaches. Nursing Inquiry, 1-12. doi:10.1111/nin.12261 
Salas, E., Grossman, R., Hughes, A. M., \& Coultas, C. W. (2015). Measuring Group Cohesion: Observations from the Science. Human Factors, 57(3), 365-374. doi: $10.1177 / 0018720815578267$

Schaefer, R. A. B., \& Erskine, L. (2012). Virtual team meetings: Reflections on a class exercise exploring technology choice. Journal of Management Education, 36(6), 777-801. doi:10.1177/1052562912436912

Shiue, Y., Chiu, C., \& Chang, C. (2010). Exploring and mitigating social loafing in online communities. Computers in Human Behavior, 26, 768-777. doi:10.1016/j.chb.2010.01.014

Shuffler, M. L., DiazGranados, D., Maynard, M. T., \& Salas, E. (2018). Developing, sustaining, and maximizing team effectiveness: An integrative, dynamic perspective of team development interventions. Academy of Management Annals, 12(2), 688-724. doi:10.5465/annals.2016.0045

Susskind, A. M., \& Odom-Reed, P. R. (2019). Team member's centrality, cohesion, conflict, and performance in multi-university geographically distributed project teams. Communication Research, 46(2), 151-178. doi:10.117/0093650215626972

Thiss, B. (2017). A delphi study: Identifying practices used to build cohesive teams in a virtual setting (Doctoral dissertation). Retrieved from http://digitalcommons.brandman.edu/edd_dissertations/123

von Treuer, K., Fuller-Tyszkiewicz, M., \& Atkinson, B. (2010). A Factor-Analytic Study Exploring the Factors of Co-Worker Cohesion. The Australian and New Zealand Journal of Organisational Psychology, 3, 42-53. doi:10.1375/ajop.3.1.42 
von Treuer, K., Fuller-Tyszkiewicz, M., Moss, S., McLeod, J., \& Hamilton, S. (2013). What are the Features and Practices of Workgroups that Epitomize Cohesion: Development of a Preliminary Measure. Journal of Business Administration Research, 2(1), 66-77. doi:10.5430/jbar.v2n1p66

von Treuer, K., McLeod, J., Fuller-Tyszkiewicz, M., \& Scott, G. (2018). Determining the components of cohesion using the repertory grid technique. Group Dynamics: Theory, Research, and Practice. 22(2), 108-128. doi:10.1037/gdn00000085

Willis, J. J. (2010). Communications management in partially distributed teams. IFAC Proceedings Volumes. 117-122. doi:10.3182/20101027-3-XK-4018.00024

Wolfe, K. A., Nelson, A. B., \& Seamster, C. L. (2018). In good company: A collaborative autoethnography describing the evolution of a successful doctoral cohort. International Journal of Doctoral Studies, 13, 293-311. doi: $10.28945 / 4078$ 


\section{SECTION SIX:}

\section{SCHOLARLY PRACTITIONER REFLECTION}


In addressing this section of the dissertation, I find it difficult to separate the influences of the doctoral program from the influences of the dissertation exercise. I have truly been a life-long learner. I began taking college classes while still in high school and have continued to expand upon my education, with a few breaks here and there, for the past 35 years. Indeed, Learner is one of my top five strengths identified by StrengthsQuest. Participating in this doctoral program and working on the dissertation has sharpened my critical thinking skills, enhanced my abilities to analyze and synthesize, and perform research at a level I was not sure I was capable of attaining.

\section{Influence on Practice}

I am no longer employed as an educational leader. However, I apply the lessons learned through participation in the doctoral program and the dissertation process regularly. There are three areas in my professional career that come to mind where my experiences with both come into play; a) my role as an instructional designer, b) analyzing leadership types, and c) the fact that I am part of a virtual, partially distributed team, which is the topic of my research.

As an instructional designer I am responsible for creating individual courses and entire curricula for various roles in a large financial institution. For each project I apply Bolman and Deal's (2013) organizational frameworks. My role places me withing the human resource division. My work is directly related to investing in employee learning and retention. I help empower employees by providing training, information, and support. Bolman and Deal (2013, pg. 135) ask the question, "Is it better to be lean and mean or to invest in people?" I believe investing in people is the most effective strategy that rewards both the employee and the company. I put forth my best effort to ensure those receiving 
the training and courses I create benefit by learning new skills and improving role performance to ensure they are successful both professionally and personally. As I create courses, company branding and image guidelines must be followed. They are important organizational symbols that are readily recognized by the public. In addition, the cultural frame is evident in the stories about the organization, employees, and customers found on its website portraying the values and ethics that are a cornerstone of the organization.

The structural lens is important for my understanding of the hierarchy of those individuals requesting, collaborating, and approving the courses I create. The political frame is closely tied to the structure. As I deal with various business lines and the personnel at different levels, I must navigate with care always remembering that each has its own interests and goals. This leads me to the second area of influence which is leadership and power.

Because of the leadership course, reference materials, and texts that were part of the coursework, I have a much better understanding of leadership styles and types of power. I regularly refer to Northouse (2016) to help me analyze a leader I may have contact with on a project. The leader I have the most contact with is my own manager. She employs multiple leadership styles, sometimes simultaneously. Overall, she is a servant leader and I am thankful for that. Because she is aware of my previous leadership experience, we often discuss the challenges of leading a group and possible solutions to various issues.

Experiences of participants in a virtual, partially distributed group regarding group cohesion is the topic of my dissertation. This topic is not just something I am interested in, it is my daily work experience. The extensive literature I have consumed to 
gather relevant information on this topic has been invaluable to me as I collaborate daily with others in a virtual manner. I am part of a core instructional design team whose membership is fairly stable with the occasional new member added to the team. I have come to understand the essential nature of group cohesion to individual and group success and overall work satisfaction for long-term groups. Throughout my dissertation journey I have shared with my team relevant research results, recommendations for developing and maintaining group cohesion, and ways to address issues that may threaten the groups cohesion.

In addition to being part of a core team, many of my projects are in collaboration with designers from other teams, project managers, relationship managers, business line representatives along with a few other roles. These projects have varying life spans from a few weeks to a few months. My understanding of the temporal nature of group cohesion has helped me recognize and accept the lack of group cohesion for short-lived projects. These groups mainly experience task cohesion. Although there are a few exceptions, once the project is complete members are unlikely to continue a relationship indicative of social cohesion.

\section{Influence as a Scholar}

The dissertation process has expanded my abilities as a scholar beyond my selfperceived capabilities. As I reflected on my growth as a scholar, I kept coming back to three main areas. First, I think I became a literature detective. Second, once I discovered relevant research, I was able to analyze it more critically than I had previously. Finally, my writing and communication skills have developed further through critical feedback, reflection, and re-writing cycles. 
When I searched for literature and studies for my dissertation I was combing through databases, journals, specific author works, and the resources they used. I felt like a detective looking for any clues to follow leading to valuable information that would help flesh out my dissertation. Once I found a promising source, I used the steps suggested by Ryan, Coughlan, and Cronin (2007) to critique the article and make notes. This process was essential for me to determine the validity of the research, stay organized, scan for pertinent information, look for bias and errors, and take notes for future use.

Previously, I thought I evaluated all media with a critical lens, but I was wrong. I now use the skills gained from the dissertation process to analyze pieces of work, such as current events news stories, political blogs, and the various statistics that supposedly support or invalidate a topic. I am also much more skeptical of accepting a study's results. This is partly because I found so much research that contradicted other research. In addition, as I went through the coding process for my own research, I used multiple methods to attempt triangulation. I discovered that, depending upon the method, I could get varying results leading to different categories and conclusions.

Finally, my writing and communication skills have expanded. I remember being told early in the program that we should write, reflect, and re-write. I feel certain that every sentence I wrote for the dissertation went through that process multiple times. I have always been particular about grammar usage and spelling, but I have become even more selective in my choice of words and sentence structure for all my communications that I send out for work and with the course content for any training I create. I have learned the value of saying more with fewer words. This has been especially valuable for 
me given the need to make my courses meaningful and effective while requiring the least amount of time from the user to complete them.

\section{Summary}

Writing this reflection has been challenging on a personal level. I have teared up, laughed, and marveled at the joyful, painful, and rewarding journey through the program and dissertation process. Although I truly considered just giving up and not finishing the dissertation portion of the program multiple times, I am glad I persevered. I learned, once again, that I am strong and not a quitter.

During the reflection process, I looked to Maslow's (1943/2005) hierarchy of needs. I believe my motivation throughout the program and dissertation process has been rooted in the need for self-actualization. Maslow defined the need for self-actualization as "a desire for self-fulfillment, namely, to the tendency for him to become actualized in what he is potentially" (pg. 171). Not giving up has raised my self-esteem because no matter how hard things became, I stuck it out. As a life-long learner, attaining this advanced degree and completing the dissertation fulfills my potential and thus my selfactualization. 


\section{References}

Al-Ani, B., Horspool, A., \& Bligh, M. C. (2011). Collaborating with 'virtual strangers': Towards developing a framework for leadership in distributed teams. Leadership, 7(3), 219-249. doi:10.1177/1742715011407382

Alsharo, M., Gregg, D., \& Ramirez, R. (2017). Virtual team effectiveness: The role of knowledge sharing and trust. Information \& Management, 54(2017), 479-490. doi:10.1016/j.im.2016.10.005

Baltaci, A., \& Balci, A. (2017). Complexity leadership: A theoretical perspective. International Journal of Educational Leadership and Management, 5(1), 30-58. doi:10.17583/ijelm.2017.2435

Berry, S. (2017). Student support networks in online doctoral programs: Exploring nested communities. International Journal of Doctoral Studies, 12, 33-48. Retrieved from http://www.informingscience.org/Publications/3676

Bhat, S. K., Pande, N., \& Ahuja, V. (2017). Virtual team effectiveness: An empirical study using SEM. Procedia Computer Science, 122(2017), 33-41. doi:10.1016/j.procs.2017.11.338

Bisbe, J., \& Sivabalan, P. (2017). Management control and trust in virtual settings: A case study of a virtual new product development team. Management Accounting Research, 37(2017), 12-29. doi:10.1016/j.mar.2017.02.001

Blair, R. (2015). Challenges faced and practical techniques for managing a dispersed group. Legal Information Management, 15(4), 248-252. doi:10.1017/S1472669615000602 
Bolman, L. G., \& Deal, T. E. (2013). Artistry, choice, \& leadership: Reframing organizations (5th ed.). San Francisco, CA: Jossey-Bass.

Bolman, L. G., \& Gallos, J. V. (2011). Reframing academic leadership (1st ed.). San Francisco, CA: Jossey-Bass.

Bonebright, D. A. (2010). 40 years of storming: A historical review of Tuckerman's model of small group development. Human Resource Development International, 13(1), 111-120. doi:10.1080/13678861003589099

Bradley, B. H., Baur, J. E., Banford, C. G., \& Postlethwaite, B. E. (2013). Team players and collective performance: How agreeableness affects team performance over time. Small Group Research, 44(6), 680-711. doi:10.1177/1046496413507609

Breuer, C., Hüffmeier, J., \& Hertel, G. (2016). Does trust matter more in virtual groups? A meta-analysis of trust and group effectiveness considering virtuality and documentation as moderators. Journal of Applied Psychology, 101(8), 11511177. doi:10.1037/ap10000113

Brown, B. C. (2011). Complexity leadership: An overview and key limitations. Integral Leadership Review. Retrieved from: http://integralleadershipreview.com/3962learner-paper-complexity-leadership/

Carless, S. A., \& De Paola, C. (2000). The measurement of cohesion in work groups. Small Group Research, 31(1), 71-88.

Carron, A. V, \& Brawley, L. R. (2012). Cohesion: Conceptual and measurement issues. Small Group Research, 43(6), 89-106. doi:10.1177/1046496412468072 
Charmaz, K. (2017a). Special invited paper: Continuities, contradictions, and critical inquiry in grounded theory. International Journal of Qualitative Methods, 16, 1-8. doi: $10.1177 / 1609406917719350$

Charmaz, K. (2017b). The power of constructivist grounded theory for critical inquiry. Qualitative Inquiry, 23(1), 34-45. doi:10.1177/1077800416657105

Charmaz, K., \& Belgrave, L. L. (2018). Thinking about data with grounded theory. Qualitative Inquiry, 1-11. doi:10.1177/1077800418809455

Cherney, M. R., Fetherston, M., \& Johnsen, L. J. (2017). Online course student collaboration literature: A review and critique. Small Group Research, 49(1), 98128. doi:10.177/1045496417721627

Chiu, Y., \& Staples, D. S. (2013). Reducing faultlines in geographically dispersed teams: Self-disclosure and task elaboration. Small Group Research, 44(5), 498-531. doi: $10.1177 / 1046196413489735$

Cogliser, C. C., Gardner, W. L., Gavin, M. B., \& Broberg, J. C. (2012). Big five personality factors and leader emergence in virtual teams: Relationships with team trustworthiness, member performance contributions, and team performance. Group \& Organization Management, 37(6), 752-784. doi: $10.1177 / 1059601112454266$

Connelly, C. E., \& Turel, O. (2016). Effects of team emotional authenticity on virtual team performance. Frontiers in Psychology, 7(Aug), 1-13. doi:10.3389/fpsyg.2006.01336

Creswell, J. W. (2012). Educational research: Planning, conducting, and evaluating quantitative and qualitative research (4th ed.). Boston, MA: Pearson Education. 
Creswell, J. W. (2014). Research design: Qualitative, quantitative, and mixed methods approaches (4th ed.). Thousand Oaks, CA: Sage.

Curators of the University of Missouri. Significant dates in the history of the University of Missouri. Retrieved from: https://muarchives.missouri.edu/sigdates.html

Daim, T. U., Ha, A., Reutiman, S., Hughes, B., Pathak, U., Bynum, W., \& Bhatla, A. (2012). Exploring the communication breakdown in global virtual teams. International Journal of Project Management, 30, 199-212. doi:10.1016/j.ijproman.2011.06.004

Eisenberg, J., Post, C., \& DiTomaso, N. (2019). Team dispersion and performance: The role of team communication and transformational leadership. Small Group Research, 1-33. doi:10.1177/1046496419827376

English, M. (2017). Group dynamics. Salem Press Encyclopedia. Toledo, OH: Great Neck Publishing.

Eubanks, D. L., Palanski, M., Olabisi, J., Joinson, A., \& Dove, J. (2016). Team dynamics in virtual, partially distributed groups: Optimal role fulfillment. Computers in Human Behavior, 61, 556-568. doi:10.1016/j.chb.2016.03.035

Eys, M. A., \& Carron, A. V. (2001). Role ambiguity, task cohesion, and task selfefficacy. Small Group Research, 32(3), 356-373.

Ferrara, S. J., Mohammadi, N., Taylor, J. E., \& Javernick-Will, A. N. (2017). Generational differences in virtual grouping in the United States: Culture, time, and technology. Journal of Information Technology in Construction, 22, 132-144.

Festinger, L. (1950). Informal social communication. Psychological Review, 57, 271282. doi: $10.1037 / \mathrm{h} 0056932$ 
Fischer, U., \& Mosier, K. (2014). The impact of communication delay and medium on team performance and communication in distributed teams. Proceedings of the Human Factors and Ergonomics Society, 115-119.

doi:10.1177/1541931214581025

Ford, R. C., Piccolo, R. F., \& Ford, L. R. (2017). Strategies for building effective virtual teams: Trust is key. Business Horizons, 60(1), 26-34. doi:10.1016/j.bushor.2016.08.009

Forrester, W. R., \& Tashchian, A. (2004). Characteristics of work groups and their relationship with social and task cohesion in student teams. Psychological Reports, 95, 207-214

French, J. R. P., Jr., \& Raven, B. (2005). The bases of social power. In J. M. Shafritz, J. S. Ott, \& Y. S. Jang (Eds.), Classics of organization theory, (6th ed.) (pp. 311320). Belmont, CA: Wadsworth, Cengage Learning.

Fuller, C. M., Marett, K., \& Twitchell, D. P. (2012). An examination of deception in virtual teams: Effects of deception on task performance, mutuality, and trust. IEEE Transactions on Professional Communication, 55(1), 20-35. doi:10.1109/TPC.2011.2172731

Gardner, S. D., \& Quigley, N. R. (n.d.). Toward a dynamic multilevel theory of group personality. Organizational Psychology Review, 5(4), 364-384. doi: $10.1177 / 2041386614532487$

Gaylon, C. E., Heaton, E. C. T., Best, T. L., \& Williams, R. L. (2016). Comparison of group cohesion, class participation, and exam performance in live and online 
classes. Social Psychology of Education, 19(1), 61-76. doi:10.1007/s11218-015$9321-y$

Gibbs, J. L., Sivunen, A., \& Boyraz, M. (2017). Investigating the impacts of group type and design on virtual group processes. Human Resource Management Review, 27(4), 590-603. doi:10.1016/j.hrmr.2016.12.006

Giles, T. M., de Lacey, S., \& Muir-Cochrane, E. (2016). Coding, constant comparisons, and core categories: A worked examples for novice constructivist grounded theorists. Advances in Nursing Science, 39(1), E29-E44. doi:

10.1097/ANS.0000000000000109

Gilson, L. L., Maynard, M. T., Young, N. C. J., Vartiainen, M., \& Hakonen, M. (2014). Virtual teams research: 10 years, 10 themes, and 10 opportunities. Journal of Management, 41,(5), 1313-1337. doi:10.1177/0149206314559946

Global Workplace Analytics. (2017). 2017 State of telecommuting in the U.S. employee workforce. Retrieved from https://cdn.thepennyhoarder.com/wpcontent/uploads/2017/06/30140000/State_Of_Telecommuting_U.S._Employee_ Workforce.pdf

González-Romá, V., \& Hernández, A. (2014). Climate uniformity: Its influence on team communication quality, task conflict, and team performance. Journal of Applied Psychology, 99(6), 1042-1058. doi:10.1037/a0037868

Greer, L. L. (2012). Group cohesion: Then and now. Small Group Research, 43(6), 655661. doi:10.1177/1046496412461532 
Grinnell, L., Sauers, A., Appunn, F., \& Mack, L. (2012). Virtual teams in higher education: The light and dark side. Journal of College Teaching \& Learning, 9(1), 65-79. doi:10.19030/tlc.v9i1.6716

Gross, N. \& Martin, W.E. (1952). On group cohesiveness. American Journal of Sociology, 57, 546-554.

Großer, B., \& Baumöl, U. (2017). Why virtual groups work - State of the art. Procedia Computer Science, 121, 297-305. doi:10.1016/j.procs.2017.11.041

Gully, S.M., Devine, D.J., \& Whitney, D.J. (2012). A meta-analysis of cohesion and performance: Effects of level of analysis and task interdependence. Small Group Research, 43(6), 702-725. doi:10.1177/1046496412468069

Haines, R. (2014). Group development in virtual groups: An experimental reexamination. Computers in Human Behavior, 39, 213-222. doi:10.1016/j.chb.2014.07.019

Hambley, L. A., O’Neill, T. A., \& Kline, T. J. B. (2007). Virtual team leadership: The effects of leadership style and communication medium on team interaction styles and outcomes. Organizational Behavior and Human Decision Processes, 103(1), 1-20. doi:10.1016/j.odhdp.2006.09.004

Harvard Business Review Press (2016). Leading virtual teams (HBR 20-minute manager series. Boston, MA: Harvard Business School Publishing Corporation.

Hemp, P., \& Stewart, T. A. (2011). Leading change when business is good: An interview with Samuel J. Palmisano. In HBR's 10 must reads on change management (pp. 35-57), Boston, MA: Harvard Business Review Press. (Reprint R0412C, Originally published in December 2004) 
Ito, J. K., \& Brotheridge, C. M. (2008). Do teams grow up one stage at a time: Exploring the complexity of group development models. Team Performance Management, 14(5-6), 214-232. doi:10.1108/13527590810898491

Jibril, T. A., \& Abdullah, M. H. (2013). Relevance of emoticons in computer-mediated communication contexts: An overview. Asian Social Science, 9(4), 201-207. doi:10.5539/ass.v9n4p201

Joyce, E. (2016, July 18). MU's diversity division begins to take shape. Missourian. Retrieved from: https://www.columbiamissourian.com/news/higher_education/mu-s-diversitydivision-begins-to-take-shape/article_303f5410-4d2e-11e6-9a979fbcf30cd6ba.html

Karvelas, K. (1998). The best of success. Franklin Lakes, NJ: Career Press.

Keller, R. (2017, September 18). University of Missouri ranks near bottom in salary comparisons. Columbia Daily Tribune. Retrieved from: https://www.columbiatribune.com/news/20170918/university-of-missouri-ranksnear-bottom-in-salary-comparisons

Kokotasaki, D., Mensies, V., \& Wiggins, A. (2016). Project-based learning: A review of the literature. Improving Schools, 19(3), 267-277. doi:10.1177/13654021665933

Kotter, J. P. (2011). Leading change: Why transformation efforts fail. In HBR's 10 must reads on change management (pp.1-16), Boston, MA: Harvard Business Review Press. (Reprint R0701J, Originally published in March 1995) 
Kozlowski, S. W. J., Chao, G. T., Grand, J. A., Braun, M. T., \& Kuljanin, G. (2013). Advancing multilevel research design: Capturing the dynamics of emergence. Organizational Research Methods, 16(4), 581-615. doi:10.1177/1094428113493119

Kozlowski, S. W. J. (2015). Advancing research on group process dynamics: Theoretical, methodological, and measurement considerations. Organizational Psychology Review, 5(4), 270-299. doi:10.1177/2041386614533586

Kozlowski, S. W. J., Chao, G. T., Grand, J. A., Braun, M. T., Kuljanin, G. (2016). Capturing the multilevel dynamics of emergence: Computational modeling, simulation, and virtual experimentation. Organizational Psychology Review, 6(1), 3-33. doi:10.1177/2041386614547955

Kramer, A., Bhave, D. P., \& Johnson, T. D. (2014). Personality and group performance: The importance of personality composition and work tasks. Personality and Individual Differences, 58, 132-137. doi:10.1016/j.paid.2013.10.019

Larson, B. Z., Vroman, S. R., \& Makarius, E. E. (March 18, 2020). A guide to managing your (newly) remote workers. Harvard Business Review. Retrieved from https://hbr.org/2020/03/a-guide-to-managing-your-newly-remote-workers

Lash, J. P. (1980, pg. 489). Helen and teacher: The story of Helen Keller and Anne Sullivan Macy. Lawrence, NY: Delacorte Press.

Levi, D. (2014). Group dynamics for groups (4th ed.). Thousand Oaks, CA: Sage. 
Lopez, M. (March 27, 2020). Stay-at-home orders could serve as an important test for the future of remote working. The Denver Channel.com. Retrieved from: https://www.thedenverchannel.com/news/360/stay-at-home-orders-could-serveas-an-important-test-for-the-future-of-remote-working

Lu, L. (2015). Building trust and cohesion in virtual teams: The developmental approach. Journal of Organizational Effectiveness, 2(1), 55-72. doi:10.1108/JOEPP-112014-0068

Marks, M. A., Mathieu, J. E., \& Zaccaro, S. J. (2001). Temporally based framework and taxonomy of team processes. The Academy of Management Review, 26(3), 356376.

Marlow, S. L., Lacerenza, C. N., \& Salas, E. (2017). Communication in virtual groups: a conceptual framework and research agenda. Human Resource Management Review, 27(4), 575-589. doi:10.1016/j.hrmr.2016.12.005

Marlow, S. L., Lacerenza, C. N., Paoletti, J., Burke, C. S., \& Salas, E. (2017). Does team communication represent a one-size-fits-all approach: A meta-analysis of team communication and performance. Organizational Behavior and Human Decision Processes, 144, 145-170. doi:10.1016/j.obhdp.2017.08.001

Maslow, A. H. (2005). A theory of human motivation. In J. M. Shafritz, J. S. Ott, \& Y. S. Jang (Eds.), Classics of organization theory (6th ed., pp. 167-178). Belmont, CA: Wadsworth. (Reprinted from Psychological Review, pp. 370-396, 1943) Mason, C. M., \& Griffin, M. A. (2003). Identifying group task satisfaction at work. Small Group Research, 34(4), 413-442. doi:10.1177/1046496403252153 
Maynard, M. T., Mathieu, J. E., Gilson, L. L., Sanchez, D. R., \& Dean, M. D. (n.d.). Do I really know you and does it matter? Unpacking the relationship between familiarity and information elaboration in global virtual groups. Group \& Organization Management, 1-35. doi:10.1177/1059601118785842

McLeod, J., \& Von Treuer, K. (2013). Towards a cohesive theory of cohesion. International Journal of Business and Social Research, 3(12), 1-11. doi:10.18533/ijbsr.v3i12.338

Merriam, S. B., \& Tisdell, E. J. (2016). Qualitative research: A guide to design and implementation. San Francisco, CA: Jossey-Bass.

Mertens, D. M. (2015). Research and evaluation in education and psychology. Thousand Oaks, CA: Sage.

Mesmer-Magnus, J. R, DeChurch, L. A., Jimenez-Rodriguez, M., Wildman, J., \& Shuffler, M. (2011). A meta-analytic investigation of virtuality and information sharing in teams. Organizational Behavior and Human Decision Processes, 115(2), 214-225. doi:10.1015/j.obhdp.2011.03.002

Mullen, B., \& Cooper, C. (1994). The relations between group cohesiveness and performance: An integration. Psychological Bulletin, 115, 210-277. doi:10.1037/0033-2909.115.2.210

Newcomer, K. E., Hatry, H. P., \& Wholey, J. S. (2015). Handbook of practical program evaluation (4th ed.). Hoboken, N.J.: John Wiley \& Sons.

Nonaka, I. (2008). The knowledge-creating company. Boston, MA: Harvard Business Press. 
Northouse, P. G. (2016). Leadership: Theory and practice (7th ed.). Thousand Oaks, CA: Sage.

Office of Budget and Planning University of Missouri System. (2019). Fiscal year 2019 budget. Retrieved from: https://www.umsystem.edu/media/fa/budget/FY2019BudgetBook.pdf

O’Neill, T. A., \& Allen, N. J. (2014). Group task conflict resolution: An examination of its linkages to group personality composition and group effectiveness outcomes. Group Dynamics, 18(2), 159-173. doi:10.1037/gdn0000004

Park, W., Kim, M., \& Gully, S. (2017). Effect of cohesion on the curvilinear relationship between group efficacy and performance. Small Group Research, 48(4), 455-481. doi:10.1177/1046496417709933

Paul, R., Drake, J. R., \& Liang, H. (2016). Global virtual group performance: The effect of coordination effectiveness, trust, and group cohesion. IEEE Transactions on Professional Communication, 59(3), 186-202. doi:10.1109/TPC.2016.2583319

Peñarroja, V., Orengo, V., Zornoza, A., Sánchez, J., \& Ripoll, P. (2015). How team feedback and team trust influence information processing and learning in virtual teams: A moderated mediation model. Computers in Human Behavior, 48, 9-16. doi:10.1016/j.chb.2015.01.034

Petter, S., \& Carter, M. (2017). In a league of their own: Exploring the impacts of shared work history for distributed online project teams. Project Management Journal, 48(1), 65-80. doi:10.1177/875697281704800105 
Radu, S. (2018, February 16). How soon will you be working from home?. U.S. News The Report. Retrieved from https://www.usnews.com/news/bestcountries/articles/2018-02-16/telecommuting-is-growing-but-still-notunanimously-embraced

Reed, A. H., \& Knight, L, V. (2009). Effect of a virtual project team environment on communication-related project risk. International Journal of Project Management,28(2010), 422-427. doi:10.1016/j.ijproman.2009.08.002

Regional Economic Development Inc. (2017-18). Facts and figures: Columbia/Boone county Missouri. Retrieved from: http://www.columbiaredi.com/wpcontent/uploads/2017/10/Fact-Book-2017.pdf

Rieger, K. L. (2018). Discriminating among grounded theory approaches. Nursing Inquiry, 1-12. doi:10.1111/nin.12261

Robert, L. P., \& You, S. (2018). Are you satisfied yet? Shared leadership, individual trust, autonomy, and satisfaction in virtual groups. Journal of the Association for Information Science and Technology, 69(4), 503-513. doi:10.1002/asi.23983

Rosen, B., Furst, S., \& Blackburn, R. (2007). Overcoming barriers to knowledge sharing in virtual teams. Organizational Dynamics, 36(3), 259-273. doi:10.1016/j.orgdyn.2007.04.007

Ryan, F., Coughlan, M., \& Cronin, P. (2007). A step-by-step guide to critiquing research. Part 2: qualitative research. British Journal of Nursing, 16(12), 738-744.

Salas, E., Grossman, R., Hughes, A. M., \& Coultas, C. W. (2015). Measuring Group Cohesion: Observations from the Science. Human Factors, 57(3), 365-374. doi:10.1177/0018720815578267 
Salas, E., Reyes, D. L., \& McDaniel, S. H. (2018). The science of groupwork: Progress, reflections, and the road ahead. American Psychologist, 73(4), 93-600. doi:10.1037/amp0000334

Salkind, N. J. (Ed.). (2010). Encyclopedia of research design: Grounded theory. Thousand Oaks, CA: Sage. doi:10.4135/9781412961288.n169

Schaefer, R. A. B., \& Erskine, L. (2012). Virtual team meetings: Reflections on a class exercise exploring technology choice. Journal of Management Education, 36(6), 777-801. doi:10.1177/1052562912436912

Schmidtke, J. M., \& Cummings, A. (2017). The effects of virtualness on teamwork behavioral components: The role of shared mental models. Human Resource Management Review, 27(4), 660-677. doi:10.1016/j.hrmr.2016.12.011

Schulze, J., \& Krumm, S. (2016). The "virtual team player": A review and initial model of knowledge, skills, abilities, and other characteristics for virtual collaboration. Organizational Psychology Review, 7(1), 66-95. doi:10.1177/2041386616675522

Schulze, J., Schultze, M., West, S. G., \& Krumm, S. (2017). The knowledge, skills, abilities, and other characteristics required for face-to-face versus computermediated communication: Similar or distinct constructs. Journal of Business and Psychology, 32, 283-300. doi:10.1007/s10869-016-9465-6

Schultz, J. R. (2010). The scholar-practitioner: A philosophy of leadership. ScholarPractitioner Quarterly, 4(1), 52-64.

Shiue, Y., Chiu, C., \& Chang, C. (2010). Exploring and mitigating social loafing in online communities. Computers in Human Behavior, 26, 768-777. doi:10.1016/j.chb.2010.01.014 
Šumanski, M. M., Kolenc, I., \& Markič (2007). Teamwork and defining group structures. Team Performance Management, 13(3/4), 102-116. doi:10.1108/13427890710759856

Susskind, A. M., \& Odom-Reed, P. R. (2019). Team member's centrality, cohesion, conflict, and performance in multi-university geographically distributed project teams. Communication Research, 46(2), 151-178. doi:10.117/0093650215626972

Thiss, B. (2017). A delphi study: Identifying practices used to build cohesive teams in a virtual setting (Doctoral dissertation). Retrieved from http://digitalcommons.brandman.edu/edd_dissertations/123

Tie, Y. C., Birks, M., \& Francis, K. (2019). Grounded theory research: A design framework for novice researchers. SAGE Open Medicine, 7, 1-8. doi:10.1177/2050312118822927

Trainer, E. H., \& Redmiles, D. F. (2018). Bridging the gap between awareness and trust in globally distributed software teams. The Journal of Systems \& Software, 144, 328-341. doi:10.1016/j.jss.2018.06.028

Tzabbar, D., \& Baburaj, Y. (2018). Optimizing the effectiveness of geographically dispersed research and development teams. Organizational Dynamics. doi:10.1016/j.orgdyn.2018.09.006

von Treuer, K., Fuller-Tyszkiewicz, M., \& Atkinson, B. (2010). A Factor-Analytic Study Exploring the Factors of Co-Worker Cohesion. The Australian and New Zealand Journal of Organisational Psychology, 3, 42-53. doi:10.1375/ajop.3.1.42 
von Treuer, K., Fuller-Tyszkiewicz, M., Moss, S., McLeod, J., \& Hamilton, S. (2013). What are the Features and Practices of Workgroups that Epitomize Cohesion: Development of a Preliminary Measure. Journal of Business Administration Research, 2(1), 66-77. doi:10.5430/jbar.v2n1p66

von Treuer, K., McLeod, J., Fuller-Tyszkiewicz, M., \& Scott, G. (2018). Determining the components of cohesion using the repertory grid technique. Group Dynamics: Theory, Research, and Practice. 22(2), 108-128. doi:10.1037/gdn00000085

Vosloban, R. I. (2012). The influence of the employee's performance on the company's growth - A managerial perspective. Procedia Economics and Finance, 3, 660665. doi:10.1016/S2212-5671(12)00211-0

Willis, J. J. (2010). Communications management in partially distributed teams. IFAC Proceedings Volumes. 117-122. doi:10.3182/20101027-3-XK-4018.00024

Wolfe, K. A., Nelson, A. B., \& Seamster, C. L. (2018). In good company: A collaborative autoethnography describing the evolution of a successful doctoral cohort. International Journal of Doctoral Studies, 13, 293-311. doi:10.28945/4078

Yilmaz, G., \& Peña, J. (2014). The Influence of Social Categories and Interpersonal Behaviors on Future Intentions and Attitudes to Form Subgroups in Virtual Groups. Communication Research, 41(3), 333-352.

doi:10.1177/0093650212443696

Yuan, L., Tu, Y., Li, J., \& Ning, L. (2018). The impact of group ability disparity and reward structure on performance. Systems Research and Behavioral Science, 35(1), 114-126. doi:10.1002/sres.2444 


\section{Appendix A}

\section{Email Invitation}

Greetings,

My name is Sandy Harding and I am a member cohort 10 of the Statewide

Cooperative EdD program. You are receiving this email invitation to participate in a study involving the cohesion aspect of group dynamics. This research is the focus of my dissertation.

First is a short survey to collect demographic data and your familiarity with virtual communication technology. Second is an interview. You may choose to only participate in the survey. If you decide to participate in the interview phase, you will engage in an interview with me via Zoom lasting 20-30 minutes.

Participation is not anonymous, but it is confidential. All identifying data collected will remain confidential.

The deadline for participation is If you are interested in volunteering your participation in this study, please let me know. My contact information is listed below.

Thank you, Sandy Harding slh8r3@mail.missouri.edu (417)274-9082 


\section{Appendix $B$}

\section{Survey Consent Form}

The following script was placed at the beginning of the electronic survey tool.

This survey is for research purposes. Participation is voluntary.

The questions are designed to gather demographic information and one to elicit your thoughts on the term "group cohesion."

If you consent to participate, please complete the survey by answering all questions and then submit.

If you do not consent to participate in the survey, there will be no adverse effects to your continuation in the statewide cooperative EdD program.

If you do not consent to participate, please exit and close the survey tool. 


\section{Survey Questions}

1. I identify as
a. Female
b. Male
c. Other
d. Prefer not to say

2. I would describe myself as (check all that apply)
a. American Indian or Alaska Native
b. Asian
c. Black or African American
d. Hispanic or Latino
e. Native Hawaiian or Other Pacific Islander
f. White
g. Other

3. My age in years is
a. Under 30
b. $31-44$
c. $46-60$
d. $60+$

4. My primary career field is
a. Elementary Education
b. Secondary Education 

c. Higher Education
d. Public Administration
e. Other

5. I have been in my primary career field for
a. Less than 5 years
b. 5-10 years
c. 11-20 years
d. 21 or more

6. I will be attending Wednesday night classes
a. In person
b. Via Zoom
c. Mostly Zoom and some in person
d. Mostly in person and some in Zoom

7. I have used virtual communication technology such as Zoom, Skype, or WebEx
a. Regularly
b. Several times
c. Rarely
d. Never

8. I am comfortable using virtual communication technology such as Zoom, Skype or WebEx.
a. Strongly disagree
b. Disagree
c. Slightly disagree 
d. Slightly agree

e. Agree

f. Strongly Agree

9. What do you think when the term "group cohesion" is mentioned. I am not looking for a technical definition. I am interested on your personal view of the term and what it means to you.

10. Would you be willing to meet with the researcher for 20-30 minutes for the interview portion of this study via Zoom? The interview will be at your convenience.
a. Yes
b. No 


\section{Appendix D}

\section{Interview Consent Form}

The following script was read to the participant prior to the start of the interview.

My name is Sandra Harding. As you know, I am completing my dissertation as part of the statewide cooperative EdD program through the University of MissouriColumbia. I am conducting a study on group cohesion and would like to ask you some questions about that. I would like to record the audio of our conversation so that I can preserve your words accurately. If at any time during the interview you feel uncomfortable answering a question, please let me know and you will not have to answer it.

If at any time you want to withdraw from this study, please tell me and I will delete the recorded audio and all related transcribed information. Withdrawal will not adversely affect your continued participation in the statewide cooperative EdD program in any way.

I will not reveal the content of our conversation to anyone as I am the sole researcher for this study. I will do everything I can to protect your privacy by securing the recorded materials on a password protected computer and a portable backup flash drive locked in a secure location.

My phone number is (417)274-9082 and my email is slh8r3@mail.missouri.edu. Your statewide cooperative EdD site coordinator also has my contact information.

Now I need to ask you if you agree to participate in this study and answer questions about your experiences with group cohesion. Do you agree to participate and allow me to record our conversation? 


\section{Appendix E}

Interview Questions

All responses are confidential.

Interviews will include both co-located and virtual group members.

Reflect upon the work or academic groups in which you have worked outside of the EdD program where you perceived a clear sense of cohesion.

1. Was this a co-located group in which members were physically present during group collaboration?

2. Describe some characteristics or features of these groups that contributed to cohesion.

3. Describe in detail a positive incident and the implications of these events on feelings of cohesion.

Reflect upon a previous work or academic group experience outside the EdD program that was not cohesive.

4. Was this a co-located group in which members were physically present during group collaboration?

5. Describe some of the characteristics or features of this group that impeded or prohibited cohesion.

6. Describe a negative incident and how this incident played a role in cohesion.

7. Thinking of the group you are currently working with to complete a course project, describe any characteristics of cohesion, if any.

8. Thinking of the group you are currently working with to complete a course project, describe any characteristics that impede or prohibit cohesion, if any. 
9. Thinking of the group you are currently working with to complete a course project, describe in detail a positive incident and the implications of these events on feelings of cohesion.

10. Thinking of the group you are currently working with to complete a course project, describe in detail a negative incident and the implications of these events on feelings of cohesion.

11. Please describe your experience with the development of cohesion in the group you are currently working with to complete a course project.

12. Given these reflections, what do you think are the essential factors that affect cohesion?

13. Share your thoughts about how the program could make adjustments to better facilitate cohesion. 
VITA

Sandra Harding graduated from Fredericktown High School in 1981 and has continued pursuing her educational goals throughout her life. She earned her associates degree from Mineral Area College in 1989. In 1996 she graduated from Southeast Missouri State University with a Bachelor of Arts in Anthropology with a minor in Sociology. She returned to Southeast Missouri State to earn a Bachelor of Science in Education in 1999. In 2000, she began her teaching career in the Marquand-Zion school district. She decided to pursue a master's in educational leadership, again from Southeast Missouri State, and graduated in 2008. She took on the role of principal for grades 7-12 while still teaching half days in the Marquand-Zion school district until 2012. Sandra was offered a position with the West Plains school district as a Senior Advisor, supervising the dual-credit students and administering the newly formed Response to Intervention program at the high school. The next year, 2013, she took an assistant principal position and remained there four more years. In 2017, she took a position with U.S. Bank as an Instructional Designer. She will complete her EdD in July of 2020. 